M. Schenk, L. Leon, K. Moshammer, P. Oßwald, T. Zeuch, L. Seidel, F. Mauss, K. Kohse-Höinghaus, Detailed mass spectrometric and modeling study of isomeric butene flames, Combust. Flame 160 (2013) 487-503

The original publication is available at www.elsevier.com

http://dx.doi.org/10.1016/j.combustflame.2012.10.023 


\section{Detailed mass spectrometric and modeling study of isomeric butene flames}

M. Schenk ${ }^{1}$, L. Leon ${ }^{2}$, K. Moshammer ${ }^{1}$, P. Oßwald ${ }^{1,4^{*}}$, T. Zeuch ${ }^{3}$, L. Seidel ${ }^{2}$, F. Mauss ${ }^{2}$, K. Kohse-Höinghaus ${ }^{1}$

1 Department of Chemistry, Bielefeld University, Universitätsstraße 25, D-33615 Bielefeld, Germany

2 Thermodynamics and Thermal Process Engineering, Brandenburg University of Technology, Siemens-Halske-Ring 8, D-03046 Cottbus, Germany

3 Institut für Physikalische Chemie, Georg-August-Universität Göttingen, Tammannstraße 6, D-37077 Göttingen, Germany

4 Now at: German Aerospace Center (DLR), Institute of Combustion Technology, Pfaffenwaldring 38-40, D-70569 Stuttgart, Germany

* Corresponding author. E-mail: patrick.osswald@dlr.de, telephone: +49 7116862 265, fax: +497116862578

\footnotetext{
Abstract

Understanding the combustion chemistry of the butene isomers is a prerequisite for a comprehensive description of the chemistry of $\mathrm{C} 1$ to $\mathrm{C} 4$ hydrocarbon and oxygenated fuels such as butanol. For the development and validation of combustion models, it is thus crucial to improve the knowledge about the $\mathrm{C} 4$ combustion chemistry in detail.

Premixed low-pressure (40 mbar) flat argon-diluted (25\%) flames of the three butene isomers (1-butene, trans-2-butene and $i$-butene) were studied under fuel-rich $(\phi=1.7)$ conditions using a newly developed analytical combination of high-resolution in-situ molecular-beam mass
} 
spectrometry (MBMS) and in-situ gas chromatography (GC). The time-of-flight MBMS with its high mass resolution enables the detection of both stable and reactive species, while the gas chromatograph permits the separation of isomers from the same sampling volume. The isomer-specific species information and the quantitative mole fraction profiles of more than 30 stable and radical species measured for each fuel were used to extend and validate the $\mathrm{C} 4$ subset of a comprehensive flame simulation model. The experimental data shows different destruction pathways for the butene isomers, as expected, and the model is well capable to predict the different combustion behavior of the isomeric flames. The detailed analysis of the reaction pathways in the flame and the respective model predictions are discussed.

\section{Introduction}

Combustion processes will remain, in the foreseeable future, a significant contribution to satisfy the increasing demand for energy. With limited availability of conventional hydrocarbon fuels, strategies for the development of alternative fuels are intensely investigated. Besides non-classical hydrocarbon fuels, such as biomass-based synthetic fuels (biomass-to-liquid; BTL) or liquefied petroleum gas (LPG), biomass-derived alcohols such as bio-butanol are widely discussed. Related demands regarding combustion efficiency and pollutant emission of such fuels require a fundamental, detailed understanding of their reaction sequences. Especially for new bio-derived fuels, uncommon classes of harmful byproducts may occur, and the emission behavior may depend strongly on the specific fuel structure [1].

In this context, recent investigations on the combustion of butanol isomers [2-6] have demonstrated the importance of the reaction subset of butene isomers and of the related $\mathrm{C} 4$ chemistry. In addition, reliable butene reaction kinetics is of crucial importance as reaction subsets for higher hydrocarbons, including e.g. n-heptane and iso-octane; also, LPG fuel 
usually contains C4 hydrocarbons in high amounts. Furthermore, novel combustion strategies, as for example in the low-temperature regime, may need revisiting of hydrocarbon mechanisms for these conditions [7]. This situation has led us to investigate the combustion behavior of all three butene isomers (namely 1-, 2-, and $i$-butene) under identical conditions in flat, premixed low-pressure flames.

Previous studies have primarily addressed combustion, oxidation, and pyrolysis of $i$-butene, whereas only few studies are available for 1-butene. Most recently, Zhang et al. [8] have investigated the pyrolysis of all three isomers including l-butene. Their study provides isomer-selective speciation of the pyrolysis products of 1-, 2-, and $i$-butene in the temperature regime between 900 and $1900 \mathrm{~K}$ and has developed a respective kinetic mechanism. Also, results from oxidation experiments $[9,10]$ and butene-doped diffusion flames [11] are available for 1-butene. Several studies have been devoted to the pyrolysis and oxidation of $i$-butene [11-18]. The latter was investigated in a turbulent flow reactor [12], shock tubes [13-16], and in a jet-stirred reactor (JSR) [17]. Dias et al. [18] have recently studied a very lean premixed $i$-butene flame at low pressure. Furthermore, recent studies have investigated the individual reaction channels of the butene isomers with $\mathrm{OH}[19]$ and $\mathrm{HO}_{2}$ [20].

In this work we present a systematic investigation of flames fueled by the three butene isomers. To the best of our knowledge this is the first detailed flame study of all butene isomers, performed under fuel-rich conditions. The destruction and growth reactions in these flames were studied in detail using electron ionization molecular-beam mass spectrometry (EI-MBMS) combined with in-situ gas chromatography (GC) from the same sampling volume. This analytical combination enables the quantitative detection of stable and reactive species by EI-MBMS and additionally the separation of isomers by gas chromatography. Experimental results from the three flames were used to validate and improve the subset of C4 kinetics in a general hydrocarbon oxidation mechanism based on the work of Hoyermann 
et al. [21]. Valuable insights into the structure-dependent combustion chemistry for the isomeric butene flames were gained from the analysis of the numerical results.

\section{Experiment and data evaluation}

\subsection{Flames and burner}

Laminar flat flames of 1-butene, trans-2-butene, and $i$-butene with a composition of butene/oxygen/argon (16.5 mol\%/58.5 mol\%/25.0 mol\%) were investigated at $40.0 \mathrm{mbar}$. The resulting stoichiometry is $\phi=1.70$, and the respective cold gas velocity was $65.6 \mathrm{~cm} / \mathrm{s}$ at $300 \mathrm{~K}$, equivalent to a total mass flux of $3.996 \times 10^{-3} \mathrm{~g} /\left(\mathrm{cm}^{2} \mathrm{~s}\right)$. The gases were regulated by calibrated mass flow controllers (MKS) with an error of less than 5\% since gas conversion factors were applied.

A home-built flat-flame burner was used; it features a sintered bronze matrix with a diameter of $64.0 \mathrm{~mm}$. The burner is mounted on a translational stage which is movable in vertical and horizontal direction. The burner chamber has an inner diameter of $320 \mathrm{~mm}$ and a height of $550 \mathrm{~mm}$.

\subsection{Molecular-beam mass spectrometry (MBMS)}

Gas samples were extracted from the flame by a quartz cone $\left(600 \mu \mathrm{m}\right.$ orifice, $25^{\circ}$ opening angle) which is mounted on a water-cooled frustum (stainless steel, $60 \mathrm{~mm}$ in height, $90^{\circ}$ opening angle). The reaction is quenched immediately when the sample is expanded into the first pumping stage chamber to a pressure of $10^{-4} \mathrm{mbar}$, forming a molecular beam which is skimmed and guided to the ion source of the mass spectrometer (pressure $10^{-6}$ mbar) by a home-made copper skimmer.

The EI-MBMS setup, described in further detail previously [2,22] consists of a two-stage Wiley-McLaren ion source combined with a reflectron time-of-flight (TOF) detection unit. 
This combination provides a high mass resolution of $\mathrm{m} / \Delta \mathrm{m} \approx 4000$ which is needed to determine the elemental composition of $\mathrm{C} / \mathrm{H} / \mathrm{O}$ species. Soft ionization using electron energies in the range between 10 and $16 \mathrm{eV}$ are typically applied to minimize undesirable fragmentation processes. In this work, nominal electron energies of 10.6, 12.0, and $13.4 \mathrm{eV}$ were employed for the detection of intermediate species, and $18.0 \mathrm{eV}$ was applied for major species determination. As detection unit serves a multichannel plate (MCP) with a multichannel scaler for data recording. The molecular-beam sampling technique preserves the gas composition of the sample and enables detection of reactive species such as radicals. In the molecular-beam modus, centerline species profiles were measured as a function of the burner-to-cone distance (h) in a so-called "burner scan".

\subsection{EI-MBMS - GC coupling}

Gas chromatography is widely used as an analytic tool for combustion diagnostics; usually it is combined with microprobe sampling $[17,23,24]$ or other off-line sampling techniques $[25,26]$. In spite of its inability to detect reactive compounds, its potential of detailed, even isomer-specific, separation of stable compounds is remarkable. For the present study, a gas chromatograph (Trace GC, Thermo Fisher Scientific) was coupled to the mass spectrometer described above. A low-pressure sampling interface was developed in order to transfer a gas sample from the first pumping stage of the MBMS setup to the high-pressure environment of the chromatograph. This is intended to provide isomer-specific information for stable intermediate species which is not available from EI-MBMS alone. The flame and sampling environment is identical for both techniques to ensure direct comparability of the results. To the best of our knowledge this is the first approach in which combined in-situ GC and MBMS enables flame diagnostics online and from the same sampling volume.

Figure 1 illustrates the MBMS system and a detailed sketch of the molecular-beam sampling arrangement with the adapted GC interface. The first pumping stage and the ionization 
chamber may be separated vacuum-tight by a gate valve located behind the skimmer. Once the molecular beam is blocked, both chambers can be reconnected by a bypass ( $6 \mathrm{~mm}$ tubing) located outside of the vessel. This bypass is connected with an 8-way valve (VICI ED48UWE) to the low-pressure sampling loop (10 $\mathrm{ml}$ sample volume) of the GC system. The arrangement allows to feed the sampled volume either into the carrier gas (helium) supply of the GC, running at 1.5 bar, or into the vacuum vessel, by establishing a connection between the first pumping stage and the ionization chamber $\left(10^{-6} \mathrm{mbar}\right)$. Pressure in the first pumping stage ranges from $\sim 10^{-4}$ mbar, when the turbomolecular pump is running, up to $\sim 10^{-1} \mathrm{mbar}$ if just the foreline rotary pump is used. The latter was done here in order to increase the sensitivity. Although the molecular flow regime is not reached under these conditions, we do not have evidence to question efficient quenching of the flame reactions. The sample thus is assumed to be representative for the respective position in the flame.

Once the loop is switched to the "sampling" position, a gas sample is withdrawn due to the pressure difference of the two chambers. Carrier gas is supplied directly to the GC in this valve position. The GC analysis will be triggered by switching the valve into the "measurement" position, where the vacuum bypass is blocked and the sampling loop is switched into the carrier gas supply. The gas sample will be compressed by the carrier gas and delivered to the GC column for temporal separation of its components. As additional features of the flame-sampling system, the low-pressure sampling loop may be used to collect any external gaseous sample, or a liquid sample may be applied through the standard injection system.

For the purpose of this investigation, the gas chromatograph was equipped with a PLOT column (Alumina BOND, $\mathrm{Na}_{2} \mathrm{SO}_{4}$ deactivation, Restek) which is suitable for the separation of small volatile hydrocarbons, especially for the separation of isomers. An appropriate temperature program from $50^{\circ} \mathrm{C}$ (hold $2.5 \mathrm{~min}$ ) to $200{ }^{\circ} \mathrm{C}$ (heating rate $20{ }^{\circ} \mathrm{C} / \mathrm{min}$, duration of 
program: $16 \mathrm{~min}$ ) was used to ensure the elution of hydrocarbon species containing up to five carbon atoms. The outlet of the column is connected via the heated transfer line directly to the ion source of the TOF-MS described above. Full mass spectra were recorded as function of the retention time. In order to reduce the recorded amount of data and to improve the signalto-noise ratio, spectra were averaged in $4.6 \mathrm{~s}(0.08 \mathrm{~min})$ intervals. Since the same instrument is used as in the MBMS setup, the same high mass resolution, high sensitivity, and soft ionization methods (e.g. soft electron ionization and laser-based photoionization) are applicable. Furthermore this enables the direct determination of fragmentation patterns for relevant flame species without the need of independent cold-gas measurements, because temporal separation of stable species can be relied upon.

\subsection{Data evaluation}

The evaluation of the molecular-beam experiment follows the routines previously used in $[2,27,28]$ for species quantification in fuel-rich flames. This strategy was only changed in minor details, and just a brief description is given here. The integrated mass signal $S$ of a species $i$ corresponds to its mole fraction $x_{i}$ in the following way:

$$
S_{i}=x_{i} \cdot c \cdot S W \cdot D_{i} \cdot \varphi \cdot F K T(h) \cdot \int \sigma_{i}(E) \cdot f(E) d E
$$

where $c$ is an instrument term, $S W$ is the number of sweeps, $D_{i}$ is the mass discrimination constant, $\varphi$ is the number of electrons, and $F K T(h)$ is the composition- and temperaturedependent sampling function. $\int \sigma_{i}(E) \cdot f(E) d E$ is the convolution of the energy distribution of the ionizing electrons with the ionization cross section. For the used instrument, the energy distribution of the electrons (full width at half maximum (FWHM) $\sim 1 \mathrm{eV}$ ) is well characterized. Because of the high-energy tail of the distribution, argon could be detected with a sufficient signal-to-noise ratio in all measurements, even when the nominal ionization 
energy was below its ionization threshold ( $\mathrm{IE}=15.759 \mathrm{eV}$ [29]). Thus Ar can be used as reference species $R$, and equation (1) may be simplified to:

$$
\frac{S_{i}}{S_{R}}=\frac{x_{i}}{x_{R}} \cdot \frac{D_{i}}{D_{R}} \cdot \frac{\int \sigma_{i}(E) f(E) d E}{\int \sigma_{R}(E) f(E) d E}=\frac{x_{i}}{x_{R}} \cdot k_{i / R}(E)
$$

where $k_{i / R}$ is the species- and energy-dependent calibration factor. Calibration factors for major species $\left(\mathrm{O}_{2}\right.$, fuel, $\mathrm{H}_{2} \mathrm{O}, \mathrm{H}_{2}, \mathrm{CO}$, and $\left.\mathrm{CO}_{2}\right)$ versus Ar were determined from an internal calibration procedure based on the direct measurement of the $\mathrm{CO} / \mathrm{CO}_{2}$ ratio and the $\mathrm{C}, \mathrm{H}$, and O element balances. Subsequently, the argon mole fraction was calculated as the balance between the sum of all species mole fractions and unity. Further information on the data evaluation procedure is provided in the Supplemental Material.

Further improvements regarding our previous evaluation routines [27] were achieved by additionally using the individual element balances to determine calibration factors for $\mathrm{O}_{2}$ and the fuel; this was done to account for their early consumption occurring in small amounts near the burner surface. The small changes of reactant mole fraction profiles caused by the use of the element balance instead of the inlet conditions were seen to improve the agreement between model and experiment. Further improvement of the data evaluation procedure resulted when intermediate species showing high mole fractions (>1\%, found for $\mathrm{CH}_{4}, \mathrm{C}_{2} \mathrm{H}_{2}$, $\mathrm{C}_{2} \mathrm{H}_{4}, \mathrm{C}_{3} \mathrm{H}_{6}$, and $\mathrm{C}_{4} \mathrm{H}_{6}$ ) were accounted for in the evaluation of the argon mole fraction profile. Furthermore, a correction of the raw signals for their background (caused by accumulation of background gas in the ionization chamber) was carried out for $\mathrm{CO}, \mathrm{CO}_{2}$, and $\mathrm{H}_{2} \mathrm{O}$. No background correction was applied for hydrogen. With this improved approach to calibration, the error is estimated to be less than $15 \%$ for major species mole fractions and less than $20 \%$ for $\mathrm{H}_{2}$.

Calibration factors $k_{i / A r}$ for reaction intermediates may be obtained by direct cold-gas calibration measurements for species for which stable gaseous cold-gas mixtures are feasible. 
For species for which a direct calibration procedure is not applicable, calibration factors were estimated either using the relative ionization cross section method (RICS) [30] or the convolution of the literature ionization cross sections with the known energy distribution of the ionizing electrons [31]. Further information is given in the Supplemental Material. To avoid fragmentation, the scan with the lowest possible energy was used for each species. Nevertheless, the agreement of species profiles for different electron energies was seen to be remarkably good in most cases. For each of the determined intermediate species, the respective calibration method, electron energy, and literature ionization cross section are listed in Table 1.

The accuracy of the experimental results is primarily dependent on the quality of calibration data available (ionization cross section, fragmentation pattern, calibration method etc.) for the respective species. Based on previous results, gained from different experimental methods and different calibration data, the maximum absolute uncertainty may be estimated for the different calibration strategies as follows. For directly calibrated species, the error is below $30 \%$; the uncertainty associated with the convolution procedure depends on the quality of the literature ionization cross section (typical uncertainty below a factor of 2). For radicals for which the RICS procedure was used, the error is estimated to be in the range of factors of 2-4. Each species is associated with an individual absolute uncertainty. However, the error is identical for all measured flames and relative comparison of trends between the flames can thus be performed with significantly higher precision.

To evaluate the GC - MBMS data, the mass signals were integrated and considered as a function of retention time. Quantitative ratios may be obtained by the determination of the peak area of a chromatographic signal and the normalization to their individual ionization cross section. Isomers were identified by determination of their individual retention times $t_{R}$. Reference values were obtained from cold-gas measurements. For this, the respective pure 
reference substance was injected as gaseous sample into the low-pressure sampling loop. Liquid substances were evaporated at room temperature using the vacuum of the first pumping stage of the MBMS system. The comparison with reference chromatograms was obtained from the reference database of the manufacturer whenever this was feasible [32]. A resolving power $\mathrm{R}$ of 0.94 was achieved for trans-2-butene and 1-butene with the current setup. This corresponds to a FWHM of $0.10 \mathrm{~min}$ (trans-2-butene) respective to $0.12 \mathrm{~min}$ (1butene). The precision for the determination of the retention time was measured to be less than \pm 0.10 min for the present setup.

\subsection{Temperature profile}

The temperature profile is crucial input for the successful kinetic modeling of onedimensional flames. Since MBMS is an invasive technique, the consideration of the influence of the sampling probe is not trivial. By introducing a sampling cone into the laminar flame, the flow and temperature fields are perturbed, and an individual deviation from the ideal behavior occurs for each burner position. Typically the influence on the measured species profiles is low for sufficiently large burner-to-cone distances [33], and the influence on the temperature field can be described adequately by using a perturbed temperature profile $[3,4,27]$.

A perturbed temperature profile may be obtained from the sampling rate of the nozzle. For the applied conditions, the sampling rate $\dot{N}$ may be expressed as:

$$
\dot{N} \propto F K T \propto p_{1 s t}=C \sqrt{\frac{\gamma}{\bar{M} T}} \cdot\left[\frac{2}{\gamma+1}\right]^{z}
$$

with $z=\frac{(\gamma+1)}{2(\gamma-1)}$. Here, FKT is the sampling function (see Eq. 1), and $p_{1 s t}$ is the pressure of the first pumping stage. The molecular flow rate $\dot{N}$ is temperature-dependent and directly proportional to the sampling function $F K T$ as well as to the pressure in the first pumping stage 
$p_{1 s t}$, assuming constant pump speed. $\gamma$ is the heat capacity coefficient $\left(C_{p} / C_{V}\right)$ and $\bar{M}$ is the mean molar mass. $C$ is an instrument-specific constant, which can be obtained at a defined position with known temperature $T$ and composition. The instrument factor is derived from the exhaust gas region where the (partial) equilibrium gas composition is precisely known and the temperature can be determined without the need of high spatial resolution. Once the factor $C$ is known, the actual gas temperature (temperature of the probed gas) can be calculated from Eq. (3) for all probed positions.

For this study, the necessary calibration temperature was obtained independently by laserinduced florescence (LIF) of seeded NO at a distance of $\mathrm{h}=21.7 \mathrm{~mm}$ without the presence of the sampling cone. For this, small amounts of NO $(<0.5 \%)$ were added to the flame, and excitation spectra were taken in the $\mathrm{A}-\mathrm{X}(0-0)$ band, detecting the broadband LIF emission. The temperature-dependent rotational ground-state population of six rotational lines was probed in the range of 225.047-225.124 nm. Experimental routines of [33] were applied using a one-dimensional LIF setup; the calibration point in the burnt gas was determined with a spatial resolution of $\sim 1 \mathrm{~mm}$.

\section{Kinetic modeling}

The chemical model is the current version of a general hydrocarbon oxidation model, first reported in [21]. In that work, the interdependence of C1-C3 species chemistry was critically evaluated by simultaneously modeling the speciation in C2 and C3 flames including benzene build-up, flame speeds, and the ignitability of various C1-C4 hydrocarbons over a broad range of combustion conditions. In recent years the model was continuously improved and augmented. Important steps were the inclusion of $n$-heptane oxidation at high and low temperatures [34], toluene combustion [35], and recently the flame chemistry of the two butane isomers [27]. 
Augmenting hydrocarbon oxidation models to larger fuels provides a critical test for the kinetic data set and the applied thermochemistry, especially when fuel degradation pathways are analyzed, which is the focus of the present work. The reason is that smaller species, here the $\mathrm{C} 1-\mathrm{C} 3$ species, are formed at different stages during the combustion process. This may imply very different relative mole fractions and temperatures, which can drastically influence the competition of elementary kinetic steps.

The kinetic model applied in this study is largely identical with the mechanism used in the preceding work on butane flame chemistry [27]. The sub-set of reactions accounting for the high-temperature oxidation of branched $\mathrm{C} 4$ species was taken from the iso-octane oxidation model of the Lawrence Livermore National Laboratory (LLNL) [36]. The thermodata of several species including the fuels and their $\mathrm{C} 4$ degradation products formed via subsequent H-atom abstraction, were updated using the thermodata of the database of Goos et al. [37]. The mechanism, thermodynamic and transport data are available in Chemkin format as supplemental data. The respective sub-mechanisms for 1 -butene, 2-butene and $i$-butene can also be found in table $\mathrm{S} 2$ in the supplemental material.

The kinetic data for several reaction steps needed modification to capture the degradation of the butene isomers. These changes include new product channels and kinetic data for reactions such as alkene $+\mathrm{OH}$ [38] and pathways for the build-up of C5 species [39]. An example for improved product channels is:

$$
\mathrm{CH}_{2}=\mathrm{CH}-\mathrm{CH}_{2}-\mathrm{CH}_{3}+\dot{\mathrm{O}} \mathrm{H} \rightarrow \mathrm{CH}_{3} \mathrm{O}+\mathrm{C}_{3} \mathrm{H}_{6} \text {. }
$$

In the absence of literature reports on mechanistic branching at high temperatures, the product pathways for some reactions were formulated on the basis of the experimental flame chemistry data presented below. Examples are:

$$
\begin{aligned}
& \mathrm{CH}_{2}=\mathrm{CH}-\mathrm{CH}_{2}-\mathrm{CH}_{3}+\mathrm{H} \rightarrow \mathrm{CH}_{3}-\mathrm{CH}=\mathrm{CH}_{2}+\dot{\mathrm{C}} \mathrm{H}_{3} \\
& \mathrm{CH}_{2}=\mathrm{CH}-\mathrm{CH}_{2}-\mathrm{CH}_{3}+\mathrm{H} \rightarrow \mathrm{CH}_{2}=\mathrm{CH}_{2}+\dot{\mathrm{C}} \mathrm{H}_{2} \mathrm{CH}_{3} .
\end{aligned}
$$


Reaction numbers refer to the numbers given in the reaction mechanism provided as supplemental material. Pressure dependence was considered when necessary, also for added reactions. For example:

$$
\dot{\mathrm{C}} \mathrm{H}_{2}-\mathrm{CH}=\mathrm{CH}_{2}+\dot{\mathrm{C}} \mathrm{H}_{3}(+\mathrm{M}) \rightarrow \mathrm{CH}_{2}=\mathrm{CH}-\mathrm{CH}_{2}-\mathrm{CH}_{3}(+\mathrm{M})
$$

We note that reactions of this pathway, ( $\mathrm{R}$ 378) and ( $\mathrm{R}$ 379) are also included in the aforementioned pyrolysis study of Zhang et al. [8].

Another modification from the original $\mathrm{C} 4$ sub-mechanism is the separation of different isomers for $\mathrm{C}_{4} \mathrm{H}_{7}$ (which were originally lumped): $\mathrm{C} 4 \mathrm{H} 7 \mathrm{P}-1\left(\mathrm{H}_{2} \mathrm{C}=\mathrm{CH}-\mathrm{CH}_{2}-\dot{\mathrm{C}} \mathrm{H}_{2}\right.$; But-3-en-1yl radical), and $\mathrm{I}-\mathrm{C} 4 \mathrm{H} 7 \quad\left(\mathrm{H}_{2} \mathrm{C}=\mathrm{C}\left(\mathrm{CH}_{3}\right) \dot{\mathrm{C}} \mathrm{H}_{2} ;\right.$ 2-methyl allyl radical). $\mathrm{C} 4 \mathrm{H} 7 \mathrm{~S}-1$ $\left(\mathrm{H}_{2} \mathrm{C}=\mathrm{CH}-\dot{\mathrm{C}} \mathrm{H}-\mathrm{CH}_{3}\right.$; But-3-en-2-yl radical $)$ is a resonance stabilized species. Similar modifications were made for 1 -butene and 2-butene where additional reactions were included and some rate coefficients were updated. The thermochemistry for $\mathrm{C} 4$ species was updated [37]. Backward rate coefficients are calculated from thermodynamic equilibrium, which is different from [36]. Furthermore rate coefficients for reactions (R 508), (R 845) and (R 852) were actualized, see supplement for details.

The minor modifications to the model only influence the mechanistic branching in the C-atom mass flow from the $\mathrm{C} 4$ fuels under study. The comprehensive character of the mechanism (see e.g. Refs. [21,34]) was maintained while the range of targets was extended to the flame chemistry of the butene isomers. A detailed report on our ongoing efforts aiming to develop an extended, compact multi-fuel component model is in preparation and beyond the scope of this work.

All calculations were performed with the premixed burner-stabilized flame module of the current version of the DARS software package [40]. First, the overall conservation equations for total mass, represented by the continuity equation, and the species are solved. The energy equation is not solved, instead the experimental temperature profile is used. The diffusion was 
calculated as mixture average diffusion, including thermal diffusion. The fresh gas composition, pressure and disturbed temperature profile are input to the numerical calculation.

The mechanism used for flame simulations in the present study consists of 163 species and 1103 irreversible reactions (forward and backward reactions are counted separately as individual, irreversible reactions). Perturbed temperature profiles were used as parameterized input curves without any shift between measurement and simulation.

\section{Results and discussion}

The discussion of individual species profiles is guided by the model-based reaction flow analysis for carbon atoms. After a short introduction into the reaction path analysis, as applied in this work, and discussion of major species and temperature profiles of the flames, a detailed analysis of the most important intermediate species will thus be given in the following section.

\subsection{Major fuel destruction pathways}

The results of the detailed reaction flux analysis are illustrated in Figs. 2-4 for the individual butene fuels. Fuel consumption pathways are commonly initiated by $\mathrm{C}-\mathrm{C}$ bond cleavage or abstraction of $\mathrm{H}$-atoms by small radicals $\left(\mathrm{H}, \mathrm{O}, \mathrm{OH}, \mathrm{HO}_{2}\right.$, etc.) from the hydrocarbon backbone. Please note that in the following discussion, some species are abbreviated using their names from the kinetic model; this is done to facilitate comparison with the reaction schemes in Figs. 2-4.

The flow analysis visualizes the flow of carbon atoms. Percentage numbers presented in the figures are the number of $\mathrm{C}$-atoms consumed by the respective reaction from the reactant molecule to the product molecule(s). The flux is normalized with the total flux of carbon atoms consumed by reactions with the reactant molecule. The figures filtered out minor 
reaction pathways, and the numbers do not add to $100 \%$. We choose atom fluxes, since atoms are, in contrast to molecules, conserved scalars. This makes fluxes at all levels of the reaction mechanism comparable.

Note that normalization to the carbon flux yields a non-molar quantity. The flow analysis of 2-butene (figure 3) for example shows that the carbon flux to form $\mathrm{C} 3$ species, (i.e. $\mathrm{C} 3 \mathrm{H} 5$ $\left(\mathrm{H}_{2} \mathrm{C}=\mathrm{CH}-\dot{\mathrm{C}} \mathrm{H}_{2}\right.$; allyl radical $)$ and $\mathrm{C} 3 \mathrm{H} 6\left(\mathrm{CH}_{2}=\mathrm{CH}-\mathrm{CH}_{3}\right.$; propene $)$ adds up to $45.5 \%$, and the amount of the corresponding $\mathrm{C} 1$ fragments (i.e. $\mathrm{CH} 3\left(\dot{\mathrm{C}}_{3}\right.$; methyl radical) and $\mathrm{CH} 3 \mathrm{O}$ $\left(\mathrm{CH}_{3} \mathrm{O}\right.$; methoxy radical)) represents $15 \%$ of the total carbon flow. The ratio of 3:1 reflects the carbon content of the reaction products.

\subsubsection{1-Butene destruction}

The breakdown of 1-butene (Fig. 2) is dominated by abstraction of either hydrogen in allyl position or $\mathrm{H}$-abstraction from the terminal methyl group. Both resulting radicals, $\mathrm{C} 4 \mathrm{H} 7 \mathrm{~S}-1$ $\left(\mathrm{H}_{2} \mathrm{C}=\mathrm{CH}-\dot{\mathrm{C}} \mathrm{H}-\mathrm{CH}_{3} ; \quad\right.$ but-3-en-2-yl $) \quad$ and $\quad \mathrm{C} 4 \mathrm{H} 7 \mathrm{P}-1 \quad\left(\mathrm{H}_{2} \mathrm{C}=\mathrm{CH}-\mathrm{CH}_{2}-\mathrm{CH}_{2} ; \quad\right.$ but-3-en-1-yl decompose by $\beta$-scission of a $\mathrm{C}-\mathrm{H}$ bond to form $\mathrm{C} 4 \mathrm{H} 6\left(\mathrm{H}_{2} \mathrm{C}=\mathrm{CH}-\mathrm{CH}=\mathrm{CH}_{2} ; 1,3\right.$-butadiene $)$. Butadiene marks the beginning of the subsequent dehydrogenation chain in which the $\mathrm{C} 4$ backbone is conserved.

In competition to the $\mathrm{H}$-abstraction, the $\mathrm{H}$-induced cleavage of a methyl group ( $\mathrm{R}$ 378) is found to be the second most important destruction channel. This reaction is the major contributor to the C3 destruction pathway. Minor contributions from the cleavage of the allylic $\mathrm{C}-\mathrm{C}$ bond to form allyl and methyl radicals additionally feed into the $\mathrm{C} 3$ route.

Final oxidation is achieved through $\mathrm{C} 2$ and $\mathrm{C} 1$ reaction sequences. The $\mathrm{C} 2$ route starts from ethene via the vinyl radical and the ketyl radical (HCCO). The $\mathrm{C} 1$ chain starts from methyl which primarily reacts over formaldehyde and the formyl radical towards $\mathrm{CO}$ and $\mathrm{CO}_{2}$. Under our fuel-rich conditions, the $\mathrm{C} 2$ route turns out to be slightly more important. However, 
numerous connections exist between the $\mathrm{C} 1$ and $\mathrm{C} 2$ paths, and both routes are fed from different species of the $\mathrm{C} 4$ and the $\mathrm{C} 3$ destruction channels.

\subsubsection{2-Butene destruction}

The destruction of 2-butene is summarized in Fig. 3. In contrast to the conditions in the 1butene flame, the H-induced breakdown towards propene is the dominating consumption pathway for this fuel:

$$
\mathrm{CH}_{3}-\mathrm{CH}=\mathrm{CH}-\mathrm{CH}_{3}+\mathrm{H} \rightarrow \mathrm{CH}_{2}=\mathrm{CH}-\mathrm{CH}_{3}+\dot{\mathrm{C}} \mathrm{H}_{3}
$$

Additional contributions to the $\mathrm{C} 3$ destruction are again seen from the $\mathrm{C}-\mathrm{C}$ bond cleavage to form allyl and methyl radicals, either directly from the fuel or after isomerization to cis-2butene (C-2-C4H8). The competing reaction towards butadiene and the $\mathrm{C} 4$ destruction route, i.e. the abstraction of a terminal $\mathrm{H}$-atom, is seen to be only of minor importance for this fuel. The final oxidation again passes through the same $\mathrm{C} 1$ and $\mathrm{C} 2$ channels as for the 1-butene flame. Consequently, these channels are supported almost exclusively from the C3 destruction products.

\subsection{3 i-Butene destruction}

Due to its branched backbone, $i$-butene exhibits some distinct differences in its destruction pathway when compared to the other butene isomers. The reaction path analysis for $i$-butene is given in Fig. 4. The dominant reaction pathway for this isomer is the $\mathrm{H}$-abstraction from one of the methyl groups to form I-C4H7 $\left(\mathrm{H}_{2} \mathrm{C}=\mathrm{C}\left(\mathrm{CH}_{3}\right) \dot{\mathrm{C}} \mathrm{H}_{2} ; 2\right.$-methyl allyl radical $)$ and the subsequent elimination of the other methyl group in order to form $\mathrm{C} 3 \mathrm{H} 4\left(\mathrm{H}_{2} \mathrm{C}=\mathrm{C}=\mathrm{CH}_{2}\right.$; allene). Again some minor contribution of the $\mathrm{C}-\mathrm{C}$ bond fission is seen also in this flame. However, in this case the $\mathrm{C}-\mathrm{C}$ bond cleavage of one methyl group opens a pathway towards $\mathrm{C} 3 \mathrm{H} 4 \mathrm{P}\left(\mathrm{HC} \equiv \mathrm{C}-\mathrm{CH}_{3}\right.$; propyne $)$ via $\mathrm{C} 3 \mathrm{H} 5-\mathrm{T}\left(\mathrm{H}_{2} \mathrm{C}=\dot{\mathrm{C}}-\mathrm{CH}_{3}\right.$; propen-2-yl radical $)$.

Because of the branched backbone, a sequential dehydrogenation to form 1,3-butadiene and the related $\mathrm{C} 4$ products is not possible for the $i$-butene fuel. Thus $\mathrm{C} 4$ hydrocarbons must be 
formed from growth products. According to the model this is primarily I-A-C5H10 $\left(\mathrm{H}_{2} \mathrm{C}=\mathrm{C}\left(\mathrm{CH}_{3}\right)-\mathrm{C}_{2} \mathrm{H}_{5} ;\right.$ 2-methyl-1-butene). The $\mathrm{C} 4$ destruction pathway, however, is of minor importance in the $i$-butene flame.

The reaction $i$-butene $+\mathrm{H}$ provides the adduct $\mathrm{I}-\mathrm{C} 4 \mathrm{H} 9\left(\dot{\mathrm{C}}\left(\mathrm{CH}_{3}\right)_{3} ; i\right.$-butyl radical $)$ in this flame which decomposes in a second step to propene, which additionally contributes to the $\mathrm{C} 3$ species pool. Note that in the current reaction subset [36] the direct formation of propene from $i$-butene is not implemented as a single-step reaction. This can be explained by steric hindrance of reactions with the central $\mathrm{C}$-atom by the branched fuel molecule. The lower propene yield in case of the $i$-butene flame indicates that propene formation from this fuel is less efficient and the implemented sub-model captures this experimental finding. The further consumption of the $\mathrm{C} 3$ species pool is again similar to that for the other isomers and occurs via $\mathrm{C} 1$ and $\mathrm{C} 2$ compounds.

\subsection{Major species}

The profiles of the major species, namely butene, $\mathrm{O}_{2}, \mathrm{Ar}, \mathrm{CO}, \mathrm{CO}_{2}, \mathrm{H}_{2}$, and $\mathrm{H}_{2} \mathrm{O}$ are summarized in Fig. 5 for the three flames. Profiles are compared with the modeling results as well as with the respective equilibrium values, indicated at $\mathrm{h}=32 \mathrm{~mm}$. The equilibrium composition for the respective exhaust gas temperature was calculated [41] using the same thermodynamic dataset [37] as applied in the detailed reaction model. Figure 5 also includes the perturbed temperature profiles (see Section 2.5) that were used as input parameters.

Considering the major species profiles and the respective temperature profiles, the global combustion behavior is very similar for the three flames. This holds in spite of the about $150 \mathrm{~K}$ lower temperature of the $i$-butene flame. This temperature difference may be due to the slightly lower heat of combustion $\left(1-\mathrm{C}_{4} \mathrm{H}_{8}: \Delta_{\mathrm{c}} \mathrm{H}^{\circ}=2716 \mathrm{~kJ} / \mathrm{mol}, 2-\mathrm{C}_{4} \mathrm{H}_{8}: 2707 \mathrm{~kJ} / \mathrm{mol}, i-\mathrm{C}_{4} \mathrm{H}_{8}\right.$ : $2699 \mathrm{~kJ} / \mathrm{mol}$ [42]) in combination with an increased heat flux towards the burner surface since 
the reaction zone of the $i$-butene flame is located slightly closer to the burner surface $(<0.5$ mm; compare e.g. $\mathrm{C}_{3} \mathrm{H}_{3}$ and $\mathrm{C}_{3} \mathrm{H}_{4}$ mole fraction profiles in Figs. 6 and 7).

In general, a very good predicting capability for the major species profiles can be noted for all butene isomers. This good agreement is valid for the profile shape as well as for the exhaust gas concentration. Note that the slightly larger deviation between experiment and simulation for the 2-butene flame is within the experimental error range. Also, lower pumping efficiency for $\mathrm{H}_{2}$ results in slightly higher experimental $\mathrm{H}_{2}$ mole fractions and minor deviations from the predictions.

\subsection{Intermediate species}

Species profiles and the respective model predictions will be discussed in this section. Following the fuel destruction sequences, we will start with the important pathways forming C3 species, followed by the dehydrogenation reactions supporting the $\mathrm{C} 4$ route, the smaller destruction products, and we will close with some selected growth products. A summary of experimental and modeling results is given in Table 1 for all measured intermediate species. Note that the experimental species profiles may be affected by the perturbance of the flow field by the nozzle. This effect is most distinct for small burner-to-cone distances. Measured data points at heights of $h \leq 1 \mathrm{~mm}$ from the burner surface are therefore less reliable and they have been displayed with open symbols in the following figures.

\subsubsection{Reaction pathways of propene and other $\mathrm{C} 3$ compounds}

The destruction of the investigated butene fuels towards propene and other C3 species is an important pathway for each fuel. Figure 6 therefore presents the first formed C3 compounds and the related soot precursors propargyl and benzene.

Propene may be formed directly from the fuel in the 1- and trans-2-butene flames by (R 378) and (R 396). For 2-butene, the direct destruction pathway towards propene is the major fuel destruction reaction, while the $i$-butene flame produces propene primarily from the $\beta$-scission 
of the $i-\mathrm{C}_{4} \mathrm{H}_{9}$ radical which, however, is formed from the fuel by $\mathrm{H}$-addition. Pathways are comparable to those found in previous studies for $n$-butane [9] and $i$-butene [14,15] even though the respective conditions (temperature range, stoichiometry, pyrolysis) differ significantly. According to results of Dias et al. [18] from a lean flame, the direct H-induced formation of propene is important also for $i$-butene.

The quantitative model prediction for propene peak concentration (compare Fig. 6) is remarkable for all butene fuels. Even without consideration of the direct, $\mathrm{H}$-induced propene channel for $i$-butene, the prediction of both profile shape and peak position is still satisfactory. Because of the perturbance of the flow field near the burner, data points at $h \leq 1 \mathrm{~mm}$ (open symbols) should not be overrated. Similarly good agreement is observed for the allyl radical, except for the 2-butene flame where allyl is somewhat over-predicted. This good agreement is also seen in the profile shapes, with the exception of a small shift $(<0.5 \mathrm{~mm})$ of the peak position in the $i$-butene flame. It is worth remembering that no additional shift was applied for comparison, neither to the modeling results nor to the perturbed temperature profile, and that the lateral uncertainty in the position is in the same order as the noted discrepancy. The allyl radical is primarily formed by $\mathrm{H}$-abstraction from propene in all flames. An additional source occurs in the flames of the linear butenes due to the fission of a respective $\mathrm{C}-\mathrm{CH}_{3}$ bond. For the $i$-butene flame, the $\mathrm{C} 3 \mathrm{H} 5-\mathrm{T}\left(\mathrm{H}_{2} \mathrm{C}=\dot{\mathrm{C}}-\mathrm{CH}_{3}\right.$; propen-2-yl radical $)$ radical formed by $\mathrm{C}-\mathrm{C}$ bond scission must be considered in addition.

The majority of allyl radicals undergoes a $\beta$-scission of the central $\mathrm{C}-\mathrm{H}$ bond to form $\mathrm{C} 3 \mathrm{H} 4$ $\left(\mathrm{H}_{2} \mathrm{C}=\mathrm{C}=\mathrm{CH}_{2}\right.$; allene $)$. Allene and its isomer $\mathrm{C} 3 \mathrm{H} 4 \mathrm{P} \quad\left(\mathrm{HC} \equiv \mathrm{C}-\mathrm{CH}_{3} ;\right.$ propyne $)$ are not distinguishable in the EI-MBMS experiment but may be separated in the GC mode. Figure 7 thus provides the profiles of the total $\mathrm{C}_{3} \mathrm{H}_{4}$ mole fraction (model and experiment) and the respective chromatograms obtained at $\mathrm{h}=3 \mathrm{~mm}$ in the three flames. Note that the experimental 
mole fractions are slightly too low since the total MBMS signal was calibrated as propyne. However, the good quality of the model prediction is similar to that for other C3 species.

Chromatographic peaks were assigned according to the reference database [32]. Note that for quantitative comparison the ionization cross sections of both species must be considered, e.g. by normalization of the respective peak area to the individual calibration factors of allene and propyne. With the cross-section-corrected propyne/allene ratio, the individual peak mole fractions can be obtained from the total $\mathrm{C}_{3} \mathrm{H}_{4}$ mole fraction measured by MBMS. According to the model prediction, the propyne/allene ratio is not independent from the position $\mathrm{h}$ once the allene peak mole fraction is passed. To avoid position-dependent effects, the respective peak mole fractions are compared. The experimental results obtained at $3 \mathrm{~mm}$ are compared to the simulations (from the respective $\mathrm{C}_{3} \mathrm{H}_{4}$ maxima) in Table 2. The individual allene and propyne mole fractions are slightly under-predicted for all flames. However, a remarkably good agreement of the propyne/allene ratio is found for all flames except for the 2-butene flame. Most of the propyne is formed by isomerization of allene in all flames, with exception of the $i$-butene flames, where an additional pathway via C3H5-T exists. Since the propene/allene ratio is remarkably similar in all flames, the isomerization appears to be fast enough, so that allene and propyne tend to be in partial equilibrium, and consequently, just small deviations of the propyne/allene ratio are seen. The further dehydrogenation of both $\mathrm{C}_{3} \mathrm{H}_{4}$ species may produce propargyl radicals which are known as important benzene and soot precursor species in most flames $[21,43]$ with non-aromatic fuels.

For the butene flames investigated here, the highest benzene mole fraction is seen in the $i$-butene flame, followed by that in the 1-and 2-butene flames, which exhibit roughly half of the amount detected in the $i$-butene flame (compare Fig. 6). This behavior can be correlated directly with the propargyl radical mole fraction in the three flames where the same concentration pattern is detected. The benzene mole fraction for the linear butene flames is 
roughly the same as measured for the comparable $i$-butane flame [27], while the amount seen in the saturated linear $n$-butane flame is again a factor of 2 lower than for the branched isomer.

\subsubsection{Fuel dehydrogenation products}

As a first dehydrogenation product, $\mathrm{C}_{4} \mathrm{H}_{7}$ radicals are produced through hydrogen abstraction from the fuel. The comparison between the model prediction (sum of all $\mathrm{C}_{4} \mathrm{H}_{7}$ isomers) and the measured mole fractions is shown in Fig. 8. The kinetic model includes three isomers for $\mathrm{C}_{4} \mathrm{H}_{7}$, namely the secondary radical C4H7S-1 $\left(\mathrm{H}_{2} \mathrm{C}=\mathrm{CH}-\dot{\mathrm{C}} \mathrm{H}-\mathrm{CH}_{3}\right.$; but-3-en-2-yl), the primary radical $\mathrm{C} 4 \mathrm{H} 7 \mathrm{P}-1 \quad\left(\mathrm{H}_{2} \mathrm{C}=\mathrm{CH}-\mathrm{CH}_{2}-\dot{\mathrm{C}} \mathrm{H}_{2} ;\right.$ but-3-en-1-yl $)$, and $\mathrm{I}-\mathrm{C} 4 \mathrm{H} 7 \quad\left(\mathrm{H}_{2} \mathrm{C}=\mathrm{C}\left(\mathrm{CH}_{3}\right) \dot{\mathrm{C}} \mathrm{H}_{2} ; 2\right.$ methyl allyl radical). The model predicts a mixture (1:2.2) of C4H7P-1 and C4H7S-1 for the l-butene flame. Here, the resonance stabilization of $\mathrm{C} 4 \mathrm{H} 7 \mathrm{~S}-1$ prevails over the higher reaction path degeneracy for the formation of $\mathrm{C} 4 \mathrm{H} 7 \mathrm{P}-1$. In the 2-butene flame, the fuel dehydrogenation product $\mathrm{C} 4 \mathrm{H} 7 \mathrm{~S}-1$ may be formed by abstraction of a terminal $\mathrm{H}$-atom; note that $\mathrm{H}_{2} \dot{\mathrm{C}}-\mathrm{CH}=\mathrm{CH}-\mathrm{CH}_{3}$ is a resonance structure of $\mathrm{C} 4 \mathrm{H} 7 \mathrm{~S}-1$. In the $i$-butene flame, $\mathrm{I}-\mathrm{C} 4 \mathrm{H} 7$ is primarily formed by the abstraction of a methyl-H from the fuel.

Since no isomer separation can be achieved for radicals in this experiment, the sum of all isomers is measured and compared to the numerical results accordingly. Note that different isomers are assumed for the experimental data reduction of the individual flames according to the model prediction. The in-situ, high-mass-resolution EI-MBMS - GC coupling as realized for the first time in this work is thus of eminent value also for the EI-MBMS data evaluation. The highest $\mathrm{C}_{4} \mathrm{H}_{7}$ mole fraction is observed in the $i$-butene flame, followed by that in the 2-butene and finally that of the 1-butene flame. Quantitative model predictions agree within experimental error for radical species for all flames. However, the total $\mathrm{C}_{4} \mathrm{H}_{7}$ mole fractions in the $i$ - and 1 -butene flames are slightly over-predicted. The prediction of the profile shape, or 
the peak position, respectively, is also satisfactory, acknowledging a $<1 \mathrm{~mm}$ shift towards higher burner distances for the $i$-butene flame.

The linear radicals formed in the 1 - and 2-butene flame can decompose via further $\mathrm{H}$-atom loss to $\mathrm{C}_{4} \mathrm{H}_{6}$ species. More precisely, 1,3-butadiene as the dominant $\mathrm{C}_{4} \mathrm{H}_{6}$ species may be formed by $\beta$-scission of the respective $\mathrm{C}-\mathrm{H}$ bonds of $\mathrm{C} 4 \mathrm{H} 7 \mathrm{~S}-1$ and $\mathrm{C} 4 \mathrm{H} 7 \mathrm{P}-1$ in the flames fueled by the linear butenes. However, this is not possible for the branched $i-\mathrm{C}_{4} \mathrm{H}_{7}$ radical formed in the $i$-butene flame. Consequently the measured mole fraction of $\mathrm{C}_{4} \mathrm{H}_{6}$ (sum of all isomers) is lowest in the $i$-butene flame while the linear fuels exhibit significantly higher mole fractions. According to the model prediction which considers 1,3-butadiene and 1,2-butadiene as $\mathrm{C}_{4} \mathrm{H}_{6}$ isomers, the major source of 1,3 -butadiene in the $i$-butene flame is I-A-C5H10 $\left(\mathrm{H}_{2} \mathrm{C}=\mathrm{C}\left(\mathrm{CH}_{3}\right)-\mathrm{C}_{2} \mathrm{H}_{5} ;\right.$ 2-methyl-1-butene $)$, formed from the $i-\mathrm{C}_{4} \mathrm{H}_{7}$ radical by methyl addition. Again the quantitative model prediction is reasonable and the profile shape is quite well captured. Almost quantitative agreement results for the $i$-butene flame, and only slight overprediction of the $\mathrm{C}_{4} \mathrm{H}_{6}$ mole fraction is observed for 1-butene, while it is somewhat underpredicted in the 2-butene flame.

For each butene flame, the isomeric composition for $\mathrm{C}_{4} \mathrm{H}_{6}$ was determined by gas chromatographic measurements performed at $\mathrm{h}=3 \mathrm{~mm}$. 1,3-Butadiene was identified as the dominant isomer in all flames, whereas only minor contributions of 1,2-butadiene, 1-, and 2-butyne were detected. For more details, see chromatograms in Fig. S1 of the supplemental material. This is again consistent with the model prediction where also 1,3-butadiene occurs almost exclusively besides minor contributions of 1,2-butadiene. For the $i$-butene flame, it is worth noting that the 1,3-butadiene mole fraction is smaller with respect to those of the other $\mathrm{C}_{4} \mathrm{H}_{6}$ isomers, which is consistent with the absence of a direct pathway towards 1,3-butadiene. This result points towards fuel-independent channels for the formation of the remaining $\mathrm{C}_{4} \mathrm{H}_{6}$ isomers, not depicted in the model. 


\subsubsection{Destruction products of 1,3-butadiene}

1,3-Butadiene is the dominant $\mathrm{C}_{4} \mathrm{H}_{6}$ isomer in all butene flames and thus the consecutive breakdown is similar in all flames. Butadiene may be destroyed via subsequent dehydrogenation until the $\mathrm{C} 4$ chain breaks apart to support the $\mathrm{C} 2$ species pool. Figure 9 shows mole fraction profiles for important species in the butadiene destruction, including $\mathrm{C} 4 \mathrm{H} 4 \quad\left(\mathrm{H}_{2} \mathrm{C}=\mathrm{CH}-\mathrm{C} \equiv \mathrm{CH} ; \quad\right.$ vinylacetylene $), \quad \mathrm{C} 4 \mathrm{H} 2 \quad(\mathrm{HC} \equiv \mathrm{C}-\mathrm{C} \equiv \mathrm{CH} ; \quad$ diacetylene $), \quad \mathrm{C} 2 \mathrm{H} 2$ ( $\mathrm{HC} \equiv \mathrm{CH}$; acetylene), and the $\mathrm{C}_{4} \mathrm{H}_{5}$ and $\mathrm{C}_{4} \mathrm{H}_{3}$ radicals. Isomer separation is not applicable for the radical species, and the sum of isomers is detected in the experiment, while the model considers $\mathrm{N}-\mathrm{C} 4 \mathrm{H} 5\left(\mathrm{H}_{2} \mathrm{C}=\mathrm{CH}-\mathrm{CH}=\dot{\mathrm{C}} \mathrm{H}\right.$; buta-1,3-dien-1-yl $)$ and $\mathrm{I}-\mathrm{C} 4 \mathrm{H} 5\left(\mathrm{H}_{2} \mathrm{C}=\mathrm{CH}-\dot{\mathrm{C}}=\mathrm{CH}_{2}\right.$; buta-1,3-dien-2-yl) as well as $\mathrm{N}-\mathrm{C} 4 \mathrm{H} 3(\mathrm{HC}=\mathrm{CH}-\mathrm{C} \equiv \mathrm{CH}$; but-1-en-3-yn-1-yl) and $\mathrm{I}-\mathrm{C} 4 \mathrm{H} 3$ $\left(\mathrm{H}_{2} \mathrm{C}=\dot{\mathrm{C}}-\mathrm{C} \equiv \mathrm{CH}\right.$; but-1-en-3-yn-2-yl). Because of the symmetry of 1,3-butadiene, two different $\mathrm{H}$-atoms may be abstracted to form either $n-\mathrm{C}_{4} \mathrm{H}_{5}$ by terminal $\mathrm{H}$-abstraction or $i-\mathrm{C}_{4} \mathrm{H}_{5}$ by abstraction of an allylic $\mathrm{H}$-atom. Both radicals react towards vinylacetylene. According to the model prediction, the route via $i-\mathrm{C}_{4} \mathrm{H}_{5}$ is favored, due to the stability of the secondary allylic radical. The respective $i$-isomers $\left(i-\mathrm{C}_{4} \mathrm{H}_{5}\right.$ and $\left.i-\mathrm{C}_{4} \mathrm{H}_{3}\right)$ were indeed identified previously as main isomers in other hydrocarbon flames [44] using photoionization techniques. Experimental values were therefore calibrated as $i-\mathrm{C}_{4} \mathrm{H}_{5}$ and $i-\mathrm{C}_{4} \mathrm{H}_{3}$, respectively. Additionally, a direct fission of the single $\mathrm{C}-\mathrm{C}$ bond in butadiene to form two vinyl radicals can in part contribute to the $\mathrm{C}_{4} \mathrm{H}_{6}$ consumption.

The quantitative agreement of experimental result and model prediction seen in Fig. 9 for $\mathrm{C}_{4} \mathrm{H}_{5}$ is acceptable for all flames, especially in view of the uncertainty for radical species calibration and of the contribution of different isomers to the experimental signal. The shoulder that can be observed in the figure is related to the species $i-\mathrm{C}_{4} \mathrm{H}_{5}$, due to the fact that it is formed faster compared to the $n-\mathrm{C}_{4} \mathrm{H}_{5}$ radical. However, it should be considered that experimental results show similar concentration levels for all flames, while the model 
prediction for 1 -butene is significantly higher than for the other flames. This effect correlates directly with the over-prediction of butadiene in the l-butene flame (see Fig. 8) and propagates through the further destruction steps towards $\mathrm{C}_{4} \mathrm{H}_{4}$ and $\mathrm{C}_{4} \mathrm{H}_{3}$. For $\mathrm{C}_{4} \mathrm{H}_{4}$, vinylacetylene is the most probable isomer, and indeed, only a single peak at $\mathrm{m} / \mathrm{z}=52.075 \mathrm{amu}$ is recorded in the chromatogram (not shown). Photoionization studies in a 1,3-butadiene flame [43] have also confirmed vinylacetylene as only detectable isomer. The model prediction capability can be considered as excellent for 1 -butene and is still good for 2- and $i$-butene. However, a relative over-prediction for 1 -butene is noted when trends are compared between the fuels.

$\mathrm{H}$-abstraction from vinylacetylene again leads either to the $n-\mathrm{C}_{4} \mathrm{H}_{3}$ or the $i-\mathrm{C}_{4} \mathrm{H}_{3}$ radical. In analogy to the partition for the $\mathrm{C}_{4} \mathrm{H}_{5}$ radicals, the mesomeric stabilization of the $i-\mathrm{C}_{4} \mathrm{H}_{3}$ isomer leads to an elevated contribution of this pathway. The situation is different for the $\mathrm{C}_{4} \mathrm{H}_{5}$ isomers, however, in that branching between channels is possible, i.e. $n-\mathrm{C}_{4} \mathrm{H}_{3}$ radicals decompose via $\mathrm{C}-\mathrm{H}$ bond scission to form $\mathrm{C}_{4} \mathrm{H}_{2}$, while $i-\mathrm{C}_{4} \mathrm{H}_{3}$ tends to decompose via $\mathrm{C}-\mathrm{C}$ bond scission to form acetylene. The quantitative agreement between experiment and model is acceptable. Relative trends are consistent with the precursor species, i.e. the noted relative over-prediction for the 1 -butene flame.

Acetylene profiles as the endpoint of this reaction chain also do not show a distinct dependence on the respective fuel structure, either in the experimental data, or in the model prediction. Moderate quantitative agreement for model and experiment is observed with a good representation of relative trends. The slightly higher deviations are not surprising, since C4 species destruction is not the major formation pathway for acetylene. 


\subsubsection{Smaller destruction products and oxygenated species}

In Fig. 10, different smaller destruction products are presented, including $\mathrm{CH}_{3}$ (methyl radical), $\mathrm{CH}_{4}$ (methane), $\mathrm{C}_{2} \mathrm{H}_{6}$ (ethane), and $\mathrm{C}_{2} \mathrm{H}_{4}$ as well as some oxygenates, namely $\mathrm{CH}_{2} \mathrm{O}$ (formaldehyde) and $\mathrm{CH}_{3} \mathrm{HCO}$ (acetaldehyde).

The quantitative model prediction of these smaller destruction products is reasonable. Profile shapes are again in good agreement with the experimental results when the first data points close to the burner are not considered because of probe effects. The respective trend, i.e. order of peak mole fractions, is predicted correctly for all C1 and C2 compounds. Methane, methyl, and formaldehyde are shown as important representatives of the $\mathrm{C} 1$ reaction chain. These compounds exhibit a comparable concentration level, in the experiment as well as in the model prediction, for all fuels. However, absolute mole fractions of methyl are somewhat over-predicted while methane is under-predicted by the model for all flames. Formaldehyde profiles, in contrast, show a slight over-prediction for 1-butene and under-prediction of approximately the same order for the 2 - and $i$-butene flames. Note that the corresponding formyl radical mole fraction (not shown) is over-predicted by a factor of $\sim 4$ in all flames, which is above the experimental error limit.

In general, aldehydes, including formaldehyde and acetaldehyde, detected in the butene flames are as low as may be expected for hydrocarbon flames [45]. In contrast to the fuelindependent formaldehyde mole fraction, acetaldehyde is seen in substantially lower concentration in the flame of the branched $i$-butene. This behavior corresponds approximately to that seen in flames of oxygenated fuels in that high acetaldehyde concentrations are found together with low soot precursor mole fractions and vice versa $[1,45]$. Note that acetaldehyde and its isomer ethenol are not separated in this study, neither experimentally nor in the numerical simulation. Since acetaldehyde was seen as major contributor to the $\mathrm{C}_{2} \mathrm{H}_{4} \mathrm{O}$ signal in many flames $[1,27,46]$, the species was calibrated accordingly. 
Ethane, ethene as well as acetylene (compare Figs. 9 and 10) are selected representatives of the $\mathrm{C} 2$ reaction chain. Again, concentration levels are similar for most $\mathrm{C} 2$ compounds in the three flames. Distinct differences may be noted for ethene and ethane which are more pronounced in the flames of the linear butenes. The model is able to reproduce this behavior, except for ethane in the $i$-butene flame for which the $\mathrm{C}_{2} \mathrm{H}_{6}$ mole fraction is slightly overpredicted.

\subsubsection{Growth products: C5 species}

As mentioned before in Section 4.3.2, C5 species must be formed by build-up reactions. Figure 11 presents mole fraction profiles for the sums of $\mathrm{C}_{5} \mathrm{H}_{8}$ and $\mathrm{C}_{5} \mathrm{H}_{10}$ isomers. Note that the C5 reaction subset of the present kinetic reaction model was primarily developed to predict the combustion behavior of $n$-hexene. The poor predictive capability for the C5 species pool is thus not surprising. Model predictions are scaled by a factor of 0.25 for comparison.

In the present numerical approach, $\mathrm{C}_{5} \mathrm{H}_{10}$ is represented as I-A-C5H10 $\left(\mathrm{CH}_{2}=\mathrm{C}\left(\mathrm{CH}_{3}\right) \mathrm{C}_{2} \mathrm{H}_{5}\right.$; 2-methyl-1-butene); it may be formed by recombination of $i$ - $\mathrm{C}_{4} \mathrm{H}_{7}$ and methyl radicals and is thus involved in the butadiene formation from $i$-butene (compare Section 4.1.3). According to the present modeling approach, it may react over different $\mathrm{C}_{5} \mathrm{H}_{9}$ radicals to form $\mathrm{I}-\mathrm{A}-\mathrm{C} 5 \mathrm{H} 8$ $\left(\mathrm{CH}_{2}=\mathrm{C}\left(\mathrm{CH}_{3}\right) \mathrm{CH}=\mathrm{CH}_{2}\right.$; isoprene $)$. Additionally, the model includes the linear $\mathrm{C} 5 \mathrm{H} 8-13$ species $\left(\mathrm{CH}_{2}=\mathrm{CH}-\mathrm{CH}=\mathrm{CH}-\mathrm{CH}_{3} ; 1,3\right.$-pentadiene $)$ but predicts almost exclusively isoprene for all three flames.

Further development of the model to predict C5 growth products depends primarily on reliable species identification as provided by the GC analysis. However, development of a full C5 sub-mechanism is beyond the scope of the present work.

Figure 12 shows the results of the $\mathrm{GC}$ measurements for $\mathrm{C}_{5} \mathrm{H}_{8}$. Signals identified as stemming from fragments or other measurement artifacts are not indicated as species. The calibration 
measurements provided reliable retention times for cyclopentene, isoprene, 1,4-pentadiene, and trans-1,3-pentadiene. In all three butene flames, four different $\mathrm{C}_{5} \mathrm{H}_{8}$ isomers were detected. The main two isomers were identified unambiguously, with predominantly isoprene $\left(t_{R}=9.49 \mathrm{~min}\right)$ and minor contributions of trans-1,3-pentadiene $\left(t_{R}=9.89 \mathrm{~min}\right)$, as indicated in Fig. 13. This result is consistent with the numerical simulation. The signal ratio of 1,3-pentadiene to isoprene is highest in the 1 -butene flame and lowest for the $i$-butene flame where almost exclusively isoprene is detected.

The $\mathrm{C}_{5} \mathrm{H}_{8}$ species related to "peak 1" ( $\left.\mathrm{t}_{\mathrm{R}}=9.26 \mathrm{~min}\right)$ and "peak 2" ( $\left.\mathrm{t}_{\mathrm{R}}=10.51 \mathrm{~min}\right)$ were also detected in all flames. Unfortunately, unambiguous identification was not possible due to the lack of reference measurements. However, assigning "peak 2" to be cis-1,3-pentadiene appears feasible since cis-isomers commonly elute later than the respective trans-isomers from the used type of column and cis-trans isomerization is possible under flame conditions.

The chromatograms for $\mathrm{C}_{5} \mathrm{H}_{10}$ from the three flames including the respective calibration measurement are shown in Fig. 13. The calibration measurement includes 3-methyl-1-butene, trans-2-pentene, $n$-pentene, 2-methyl- 1 -butene, and cis-2-pentene. In the 1 -butene and 2-butene flame, trans-2-pentene $\left(t_{R}=8.38 \mathrm{~min}\right)$ was identified as the main isomer which is also present in the $i$-butene flame. Regarding the limited precision in determining $t_{\mathrm{R}}( \pm 0.10 \mathrm{~min})$, the second signal ("peak 3") could not be assigned unambiguously. Possible isomers are 2-methyl-1-butene, $n$-pentene, and cis-2-pentene. Again, the corresponding cis-isomer (cis-2pentene) appears to be most likely for the linear butene flames.

In the $i$-butene flame, the ratio of the isomers is clearly different; here, a minor contribution from trans-2-pentene is seen. The second isomer in this flame can most probably be assigned to be 2-methyl-1-butene. 2-Methyl-1-butene (I-A-C5H10) may be formed from recombination of $i-\mathrm{C}_{4} \mathrm{H}_{7}$ and the methyl radical. This reaction is also seen in the simulation to be important for the formation of the linear C4 species pool in this flame (compare Section 4.3.2). 
Consequently, $\mathrm{C}_{5} \mathrm{H}_{10}$ and its dehydrogenation product isoprene are favored in the $i$-butene flame compared to the 1- and 2-butene flames, where the total $\mathrm{C}_{5} \mathrm{H}_{8}$ mole fractions are also about a factor of 2 smaller.

\section{Summary and conclusions}

To support the development of reliable detailed reaction kinetics for the high-temperature oxidation of hydrocarbons, we have investigated the flames of the three butene isomers. The C4 hydrocarbon reaction chemistry is an important subset for LPG and other hydrocarbon fuels. It is also of importance as a reaction subset for the destruction of the butanol isomers, some of which are discussed as potential biofuels. Existing reaction models $[3,4]$ have highlighted the importance of the water elimination reaction which may form butene isomers from the respective butanol fuel. However, both studies were focused on the butanol breakdown, and higher hydrocarbon species (including the butene destruction products) are either not reported due to the poor model prediction [3] or the reported trends are not in good agreement with the experimental results [4]. The present study may contribute to the improvement of the respective models.

In this work, mole fraction profiles of 36 species were measured in fuel-rich flat butene flames using molecular-beam mass spectrometry. The identification of the species pool relied on the determination of the elemental composition of the involved species, with additional isomer-specific analysis, achieved by coupling in-situ gas chromatography to the molecularbeam experiment. This setup enables direct application of both analysis techniques without changing the flame environment.

The resulting detailed species information was used to improve the $\mathrm{C} 4$ reaction chemistry of an extensive, dedicated hydrocarbon oxidation mechanism [21]. A single mechanism which considers more than 160 species, connected by more than 1100 reactions (counting forward 
and calculated backward steps separately), was used to predict the structure of all three flames. For appropriate modeling application, perturbed temperature profiles were derived directly from the mass spectrometric experiments and calibrated by optical measurements. In general, the predicting capability of the presented kinetic model is very good for the major combustion products as well as for many intermediate species for all three fuels. This good agreement is valid for profile shapes as well as for the quantitative mole fraction results. Twothirds of the species smaller than the fuel molecule are predicted within the experimental error. All major trends, including relative mole fraction patterns observed between the individual fuels are reliably represented by the model.

A detailed analysis of the respective reaction sequences was performed based on the detailed mechanism. All three butene fuels are primarily destroyed following a C4 route and a C3 route with varying importance. The $\mathrm{C} 3$ route via propene, allene, and propyne is a strong destruction pathway for all three isomers. For the $i$-butene flame, this pathway occurs almost exclusively, because of the branched backbone of the fuel molecule. However, the $\mathrm{C} 4$ route via 1,3-butadiene and vinylacetylene is of crucial importance for the linear isomers 1 - and 2-butene.

Indeed, the total $\mathrm{C}_{3} \mathrm{H}_{4}$ to $\mathrm{C}_{4} \mathrm{H}_{4}$ peak mole fraction ratio which may serve as an indicator of the C3:C4 pathway ratio is approximately 5:1 for the 1-butene flame and 3:2 in the 2-butene flame. This is quite close to the ratio observed in a butadiene flame [43] (roughly 1:1) which is primarily destroyed through the $\mathrm{C} 4$ pathway. On the other hand, the $\mathrm{C}_{3} \mathrm{H}_{4}$ to $\mathrm{C}_{4} \mathrm{H}_{4}$ peak mole fraction ratio in the $i$-butene flame of roughly $7: 1$ is the same as the ratio observed in neat propene flames of $~ 7: 1$ [47] which highlights the strong C3 pathway for this fuel isomer. Similar trends can be observed in flames of the butane isomers [27], where a $\mathrm{C}_{3} \mathrm{H}_{4}$ to $\mathrm{C}_{4} \mathrm{H}_{4}$ peak mole fraction ratio of about 5:1 is observed for the branched $i$-butane and 5:2 for the linear $n$-butane flame. 


\section{Acknowledgements}

The authors wish to thank Ulf Struckmeier for his contributions to Fig. 1. Furthermore, they are grateful to Regine Schröder for assistance with typing the manuscript. Financial support of this project by Deutsche Forschungsgemeinschaft (DFG) within the large-scale research structure SFB 686 "Model-based control of homogenized low-temperature combustion", TP B3, is gratefully acknowledged.

\section{References}

[1] K. Kohse-Höinghaus, P. Oßwald, T.A. Cool, T. Kasper, N. Hansen, F. Qi, C.K. Westbrook, P.R. Westmoreland, Angew. Chem. Int. Ed. 49 (2010) 3572-3597.

[2] P. Oßwald, H. Güldenberg, K. Kohse-Höinghaus, B. Yang, T. Yuan, F. Qi, Combust. Flame 158 (2011) 2-15.

[3] S.M. Sarathy, S. Vranckx, K. Yasunaga, M. Mehl, P. Oßwald, W.K. Metcalfe, C.K. Westbrook, W.J. Pitz, K. Kohse-Höinghaus, R.X. Fernandes, H.J. Curran, Combust. Flame 159 (2012) 2028-2055.

[4] A. Frassoldati, R. Grana, T. Faravelli, E. Ranzi, P. Oßwald, K. Kohse-Höinghaus, Combust. Flame 159 (2012) 2295-2311.

[5] P.S. Veloo, Y.L. Wang, F.N. Egolfopoulos, C.K. Westbrook, Combust. Flame 157 (2010) 1989-2004.

[6] M.R. Harper, K.M. Van Geem, S.P. Pyl, G.B. Marin, W.H. Green, Combust. Flame 158 (2011) 16-41.

[7] J. Zádor, C.A. Taatjes, R.X. Fernandes, Prog. Energy Combust. Sci. 37 (2011) 371-421.

[8] Y. Zhang, J. Cai, L. Zhao, J. Yang, H. Jin, Z. Cheng, Y. Li, L. Zhang, F. Qi, Combust. Flame 159 (2012) 905-917. 
[9] B. Heyberger, N. Belmekki, V. Conraud, P.-A. Glaude, R. Fournet, F. Battin-Leclerc, Int. J. Chem. Kinet. 34 (2002) 666-677.

[10] A. Chakir, M. Cathonnet, J.C. Boettner, F. Gaillard, Proc. Combust. Inst. 22 (1989) 873-881.

[11] C.S. McEnally, L.D. Pfefferle, Combust. Flame 115 (1998) 81-92.

[12] F.L. Dryer, K. Brezinsky, Combust. Sci. Technol. 45 (1986) 199-212.

[13] K. Yasunaga, Y. Kuraguchi, R. Ikeuchi, H. Masaoka, O. Takahashi, T. Koike, Y. Hidaka, Proc. Combust. Inst. 32 (2009) 453-460.

[14] W. Tsang, J.A. Walker, Proc. Combust. Inst. 22 (1989) 1015-1022.

[15] H.J. Curran, M.P. Dunphy, J.M. Simmie, C.K. Westbrook, W.J. Pitz, Proc. Combust. Inst. 24 (1992) 769-776.

[16] J.C. Bauge, F. Battin-Leclerc, F. Baronnet, Int. J. Chem. Kinet. 30 (1998) 629-640.

[17] P. Dagaut, M. Cathonnet, Combust. Sci. Technol. 137 (1998) 237-275.

[18] V. Dias, J. Vandooren, Fuel 89 (2010) 2633-2639.

[19] S.S. Vasu, L.K. Huynh, D.F. Davidson, R.K. Hanson, D.M. Golden, J. Phys. Chem. A 115 (2011) 2549-2556.

[20] J. Zádor, S.J. Klippenstein, J.A. Miller, J. Phys. Chem. A 115 (2011) 10218-10225.

[21] K. Hoyermann, F. Mauß, T. Zeuch, Phys. Chem. Chem. Phys. 6 (2004) 3824-3835.

[22] A. Lucassen, N. Labbe, P.R. Westmoreland, K. Kohse-Höinghaus, Combust. Flame 158 (2011) 1647-1666.

[23] H.A. Gueniche, P.A. Glaude, G. Dayma, R. Fournet, F. Battin-Leclerc, Combust. Flame 146 (2006) 620-634.

[24] N.M. Marinov, W.J. Pitz, C.K. Westbrook, A.M. Vincitore, M.J. Castaldi, S.M. Senkan, C.F. Melius, Combust. Flame 114 (1998) 192-213.

[25] R. Ancia, P.J. van Tiggelen, J. Vandooren, Combust. Flame 116 (1999) 307-309. 
[26] A. Turbiez, P. Devynck, P. Desgroux, J.F. Pauwels, Rev. Sci. Instrum. 70 (1999) 28282835.

[27] P. Oßwald, K. Kohse-Höinghaus, U. Struckmeier, T. Zeuch, L. Seidel, L. Leon, F. Mauss, Z. Phys. Chem. 225 (2011) 1029-1054.

[28] T. Kasper, P. Oßwald, U. Struckmeier, K. Kohse-Höinghaus, C.A. Taatjes, J. Wang, T.A. Cool, M.E. Law, A. Morel, P.R. Westmoreland, Combust. Flame 156 (2009) 11811201.

[29] S.G. Lias, J.E. Bartmess, J.F. Liebman, J.L. Holmes, R.D. Levin, W.G. Mallard, S.A. Kafafi, "Ion Energetics Data" in NIST Chemistry WebBook, NIST Standard Reference Database Number 69, Eds. P.J. Linstrom and W.G. Mallard, National Institute of Standards and Technology, Gaithersburg MD, 20899, http://webbook.nist.gov

[30] J.C. Biordi, Prog. Energy Combust. Sci. 3 (1977) 151-173.

[31] F. Herrmann, P. Oßwald, K. Kohse-Höinghaus, Proc. Combust. Inst. 34 (2012), DOI: 10.1016/j.proci.2012.06.136

[32] Restek Corporation, "Lit. Cat.\# PCBR1163B-UNV" in Restek Searchable Chromatogram Library, http://www.restek.com/pdfs/PCBR1163B-UNV.pdf

[33] U. Struckmeier, P. Oßwald, T. Kasper, L. Böhling, M. Heusing, M. Köhler, A. Brockhinke, K. Kohse-Höinghaus, Z. Phys. Chem. 223 (2009) 503-537.

[34] S.S. Ahmed, F. Mauß, G. Moréac, T. Zeuch, Phys. Chem. Chem. Phys. 9 (2007) 1107 1126.

[35] S.S. Ahmed, F. Mauß, T. Zeuch, Z. Phys. Chem. 223 (2009) 551-563.

[36] H.J. Curran, P. Gaffuri, W.J. Pitz, C.K. Westbrook, Combust. Flame 129 (2002) 253280. 
[37] E. Goos, A. Burcat, B. Ruscic, Extended Third Millennium Ideal Gas and Condensed Phase Thermochemical Database for Combustion with Updates from Active Thermochemical Tables, http://www.dlr.de/vt/

[38] L.K. Huynh, K. Barriger, A. Violi, J. Phys. Chem. A 112 (2008) 1436-1444.

[39] M. Mehl, G. Vanhove, W.J. Pitz, E. Ranzi, Combust. Flame 155 (2008) 756-772.

[40] Lund Combustion Engineering, DARS: Digital Analysis of Reaction Systems, http://www.loge.se/Products/DARS-Basic.html

[41] C. Morley, Gaseq: Chemical equilibria in perfect gases, http://www.c.morley.dsl.pipex.com

[42] P.J. Linstrom, W.G. Mallard, NIST Chemistry WebBook, NIST Standard Reference Database Number 69, http://webbook.nist.gov

[43] N. Hansen, J.A. Miller, T. Kasper, K. Kohse-Höinghaus, P.R. Westmoreland, J. Wang, T.A. Cool, Proc. Combust. Inst. 32 (2009) 623-630.

[44] N. Hansen, S.J. Klippenstein, C.A. Taatjes, J.A. Miller, J. Wang, T.A. Cool, B. Yang, R. Yang, L. Wei, C. Huang, J. Wang, F. Qi, M.E. Law, P.R. Westmoreland, J. Phys. Chem. A 110 (2006) 3670-3678.

[45] J. Wang, U. Struckmeier, B. Yang, T.A. Cool, P. Osswald, K. Kohse-Höinghaus, T. Kasper, N. Hansen, P.R. Westmoreland, J. Phys. Chem. A 112 (2008) 9255-9265.

[46] N. Hansen, J.A. Miller, P.R. Westmoreland, T. Kasper, K. Kohse-Höinghaus, J. Wang, T.A. Cool, Combust. Flame 156 (2009) 2153-2164.

[47] K. Kohse-Höinghaus, P. Oßwald, U. Struckmeier, T. Kasper, N. Hansen, C.A. Taatjes, J. Wang, T.A. Cool, S. Gon, P.R. Westmoreland, Proc. Combust. Inst. 31 (2007) 11191127.

[48] K.N. Joshipura, M. Vinodkumar, U.M. Patel, J. Phys. B: At. Mol. Opt. Phys. 34 (2001) $509-519$. 
[49] O.J. Orient, S.K. Srivastava, J. Phys. B: At. Mol. Opt. Phys. 20 (1987) 3923-3936.

[50] W.L. Fitch, A.D. Sauter, Anal. Chem. 55 (1983) 832-835.

[51] Y.-K. Kim, K.K. Irikura, M.E. Rudd, M.A. Ali, P.M. Stone, J.S. Coursey, R.A. Dragoset, A.R. Kishore, K.J. Olsen, A.M. Sansonetti, G.G. Wiersma, D.S. Zucker, M.A. Zucker, Electron-Impact Cross Sections for Ionization and Excitation, http://physics.nist.gov/PhysRefData/Ionization/Xsection.html

[52] H. Nishimura, H. Tawara, J. Phys. B: At. Mol. Opt. Phys. 27 (1994) 2063-2074. 
Table 1. Intermediate species measured with MBMS and comparison with numerical results in the butene flames. M: nominal mass; E: electron energy; IE: ionization threshold; calibration method: "RICS" (of reference species in parenthesis), "convolution" (of energy distribution and ionization cross section) or "direct" (cold-gas calibration); $\mathrm{x}_{\max }$ : peak mole fraction. For the following species, $\mathrm{x}_{\max }$ refers to the sum of all isomers (in the MBMS experiment and the simulations): $\mathrm{C}_{3} \mathrm{H}_{4}, \mathrm{C}_{3} \mathrm{H}_{5}, \mathrm{C}_{4} \mathrm{H}_{3}, \mathrm{C}_{4} \mathrm{H}_{5}, \mathrm{C}_{4} \mathrm{H}_{6}, \mathrm{C}_{4} \mathrm{H}_{7}, \mathrm{C}_{5} \mathrm{H}_{8}, \mathrm{C}_{6} \mathrm{H}_{4}$, and $\mathrm{C}_{6} \mathrm{H}_{6}$. Detailed information regarding the isomeric composition can be found in the Supplemental Material.*: for $\mathrm{H}, \mathrm{O}, \mathrm{OH}$ and $\mathrm{HO}_{2}$, no experimental data are available.

\begin{tabular}{|c|c|c|c|c|c|c|c|c|c|c|c|c|}
\hline \multirow{2}{*}{ Species } & \multirow{2}{*}{$\mathbf{M}$} & \multirow{2}{*}{$E(e V)$} & \multirow{2}{*}{ IE (eV) } & \multirow{2}{*}{ Calibrated as } & \multirow{2}{*}{ Calibration method } & \multirow{2}{*}{ Ref. } & \multicolumn{2}{|c|}{ 1-butene } & \multicolumn{2}{|c|}{ 2-butene } & \multicolumn{2}{|c|}{$i$-butene } \\
\hline & & & & & & & $\mathbf{x}_{\max } \operatorname{Exp.}$ & $\mathbf{x}_{\max }$ Model & $\mathbf{x}_{\max }$ Exp. & $\mathbf{x}_{\max }$ Model & $\mathbf{x}_{\max } \operatorname{Exp.}$ & $\mathbf{x}_{\max }$ Model \\
\hline $\mathrm{H}$ & 1 & $*$ & 13.598 & Hydrogen atom & $*$ & {$[48]$} & $*$ & $3.6 \mathrm{E}-02$ & $*$ & $3.7 \mathrm{E}-02$ & $*$ & $3.2 \mathrm{E}-02$ \\
\hline $\mathrm{CH}_{3}$ & 15 & 10.6 & 9.8 & Methyl radical & $\operatorname{RICS}\left(\mathrm{CH}_{4}\right)$ & {$[48]$} & 4.3E-03 & $1.3 \mathrm{E}-02$ & $5.6 \mathrm{E}-03$ & $1.3 \mathrm{E}-02$ & $5.7 \mathrm{E}-03$ & $1.5 \mathrm{E}-02$ \\
\hline $\mathrm{O}$ & 16 & $*$ & 14 & Oxygen atom & $*$ & {$[51]$} & $*$ & $2.0 \mathrm{E}-03$ & $*$ & $2.1 \mathrm{E}-03$ & $*$ & $1.9 \mathrm{E}-03$ \\
\hline $\mathrm{CH}_{4}$ & 16 & 13.4 & 12.6 & Methane & Direct & [49] & $1.4 \mathrm{E}-02$ & 7.6E-03 & $1.2 \mathrm{E}-02$ & 7.4E-03 & $1.1 \mathrm{E}-02$ & $5.6 \mathrm{E}-03$ \\
\hline $\mathrm{OH}$ & 17 & $*$ & 13.017 & Hydroxyl radical & $*$ & [29] & $*$ & $1.0 \mathrm{E}-02$ & $*$ & $1.0 \mathrm{E}-02$ & $*$ & $8.0 \mathrm{E}-03$ \\
\hline $\mathrm{C}_{2} \mathrm{H}_{2}$ & 26 & 12 & 11.4 & Acetylene & Direct & {$[50]$} & $3.9 \mathrm{E}-02$ & $2.2 \mathrm{E}-02$ & $3.6 \mathrm{E}-02$ & $2.2 \mathrm{E}-02$ & $3.3 \mathrm{E}-02$ & $2.3 \mathrm{E}-02$ \\
\hline $\mathrm{C}_{2} \mathrm{H}_{3}$ & 27 & 10.6 & 9 & Vinyl radical & $\operatorname{RICS}\left(\mathrm{C}_{2} \mathrm{H}_{4}\right)$ & [51] & $9.7 \mathrm{E}-06$ & $1.1 \mathrm{E}-03$ & $1.5 \mathrm{E}-05$ & $8.8 \mathrm{E}-04$ & $1.4 \mathrm{E}-05$ & $6.9 \mathrm{E}-04$ \\
\hline $\mathrm{C}_{2} \mathrm{H}_{4}$ & 28 & 10.6 & 10.5 & Ethene & Direct & {$[52]$} & $2.3 \mathrm{E}-02$ & $2.4 \mathrm{E}-02$ & $1.6 \mathrm{E}-02$ & $1.5 \mathrm{E}-02$ & $8.9 \mathrm{E}-03$ & $1.1 \mathrm{E}-02$ \\
\hline $\mathrm{C}_{2} \mathrm{H}_{5}$ & 29 & 10.6 & 8.1 & Ethyl radical & $\operatorname{RICS}\left(\mathrm{C}_{2} \mathrm{H}_{6}\right)$ & {$[50]$} & $1.8 \mathrm{E}-04$ & $6.6 \mathrm{E}-04$ & $8.1 \mathrm{E}-05$ & $1.9 \mathrm{E}-04$ & $6.9 \mathrm{E}-05$ & $1.6 \mathrm{E}-04$ \\
\hline $\mathrm{HCO}$ & 29 & 10.6 & 8.1 & Formyl radical & Convolution & {$[51]$} & $4.5 \mathrm{E}-05$ & $1.9 \mathrm{E}-04$ & $3.8 \mathrm{E}-05$ & $1.6 \mathrm{E}-04$ & $5.9 \mathrm{E}-05$ & $1.2 \mathrm{E}-04$ \\
\hline $\mathrm{C}_{2} \mathrm{H}_{6}$ & 30 & 12 & 11.5 & Ethane & Direct & {$[52]$} & 4.7E-03 & $4.3 \mathrm{E}-03$ & $5.2 \mathrm{E}-03$ & $5.7 \mathrm{E}-03$ & $2.9 \mathrm{E}-03$ & $4.0 \mathrm{E}-03$ \\
\hline $\mathrm{CH}_{2} \mathrm{O}$ & 30 & 12 & 10.9 & Formaldehyde & Convolution & [51] & $4.8 \mathrm{E}-03$ & $5.9 \mathrm{E}-03$ & $4.5 \mathrm{E}-03$ & $3.1 \mathrm{E}-03$ & $4.2 \mathrm{E}-03$ & $3.5 \mathrm{E}-03$ \\
\hline $\mathrm{HO}_{2}$ & 33 & $*$ & 11.35 & Hydroperoxy radical & $*$ & {$[29]$} & $*$ & $2.7 \mathrm{E}-04$ & $*$ & $2.9 \mathrm{E}-04$ & $*$ & $1.7 \mathrm{E}-04$ \\
\hline $\mathrm{C}_{3} \mathrm{H}_{3}$ & 39 & 10.6 & 8.7 & Propargyl radical & $\operatorname{RICS}\left(\mathrm{C}_{3} \mathrm{H}_{6}\right)$ & [51] & $1.0 \mathrm{E}-03$ & $1.1 \mathrm{E}-03$ & $6.9 \mathrm{E}-04$ & $1.3 \mathrm{E}-03$ & $2.4 \mathrm{E}-03$ & $1.9 \mathrm{E}-03$ \\
\hline $\mathrm{C}_{3} \mathrm{H}_{4}$ & 40 & 10.6 & 10.4 & Propyne & $\operatorname{RICS}\left(\mathrm{C}_{3} \mathrm{H}_{6}\right)$ & [51] & $4.3 \mathrm{E}-03$ & $6.7 \mathrm{E}-03$ & $3.4 \mathrm{E}-03$ & $8.0 \mathrm{E}-03$ & $1.2 \mathrm{E}-02$ & $1.5 \mathrm{E}-02$ \\
\hline $\mathrm{C}_{3} \mathrm{H}_{5}$ & 41 & 10.6 & 8.1 & Allyl radical & $\operatorname{RICS}\left(\mathrm{C}_{3} \mathrm{H}_{6}\right)$ & {$[51]$} & $2.2 \mathrm{E}-03$ & $2.0 \mathrm{E}-03$ & $9.2 \mathrm{E}-04$ & $1.9 \mathrm{E}-03$ & $8.1 \mathrm{E}-04$ & $1.2 \mathrm{E}-03$ \\
\hline $\mathrm{C}_{2} \mathrm{H}_{2} \mathrm{O}$ & 42 & 10.6 & 9.6 & Ketene & Convolution & $\operatorname{RICS}\left(\mathrm{C}_{2} \mathrm{H}_{6} \mathrm{O}\right)$ & $5.5 \mathrm{E}-04$ & $3.5 \mathrm{E}-04$ & $5.9 \mathrm{E}-04$ & $3.2 \mathrm{E}-04$ & $7.5 \mathrm{E}-04$ & $6.9 \mathrm{E}-04$ \\
\hline $\mathrm{C}_{3} \mathrm{H}_{6}$ & 42 & 10.6 & 9.7 & Propene & Direct & {$[52]$} & $9.4 \mathrm{E}-03$ & $8.4 \mathrm{E}-03$ & $1.5 \mathrm{E}-02$ & $1.2 \mathrm{E}-02$ & $5.6 \mathrm{E}-03$ & $7.5 \mathrm{E}-03$ \\
\hline
\end{tabular}




\begin{tabular}{|c|c|c|c|c|c|c|c|c|c|c|c|c|}
\hline \multirow{2}{*}{ Species } & \multirow{2}{*}{$\mathbf{M}$} & \multirow{2}{*}{$\mathrm{E}(\mathrm{eV})$} & \multirow{2}{*}{ IE $(e V)$} & \multirow{2}{*}{ Calibrated as } & \multirow{2}{*}{ Calibration method } & \multirow{2}{*}{ Ref. } & \multicolumn{2}{|c|}{ 1-butene } & \multicolumn{2}{|c|}{ 2-butene } & \multicolumn{2}{|c|}{$i$-butene } \\
\hline & & & & & & & $\mathbf{x}_{\max } \operatorname{Exp}$ & $\mathbf{x}_{\text {max }}$ Model & $\mathbf{x}_{\max }$ Exp. & $\mathbf{x}_{\text {max }}$ Model & $\mathbf{x}_{\max }$ Exp. & $\mathbf{x}_{\max }$ Model \\
\hline $\mathrm{C}_{2} \mathrm{H}_{4} \mathrm{O}$ & 44 & 10.6 & 10.2 & Acetaldehyde & Direct & {$[50]$} & $8.4 \mathrm{E}-04$ & $9.6 \mathrm{E}-04$ & $7.5 \mathrm{E}-04$ & $1.3 \mathrm{E}-03$ & $2.8 \mathrm{E}-04$ & $3.4 \mathrm{E}-04$ \\
\hline $\mathrm{C}_{4} \mathrm{H}_{2}$ & 50 & 10.6 & 10.2 & Diacetylene & Convolution & {$[51]$} & $2.5 \mathrm{E}-03$ & $1.8 \mathrm{E}-03$ & $1.9 \mathrm{E}-03$ & $1.5 \mathrm{E}-03$ & $3.3 \mathrm{E}-03$ & $1.3 \mathrm{E}-03$ \\
\hline $\mathrm{C}_{4} \mathrm{H}_{3}$ & 51 & 10.6 & 8.02 & But-1-en-3-yn-2-yl & Convolution & $\operatorname{RICS}\left(\mathrm{C}_{4} \mathrm{H}_{4}\right)$ & $1.9 \mathrm{E}-05$ & $9.8 \mathrm{E}-05$ & 9.1E-05 & 7.7E-05 & $2.1 \mathrm{E}-05$ & 5.2E-05 \\
\hline $\mathrm{C}_{4} \mathrm{H}_{4}$ & 52 & 10.6 & 9.6 & Vinylacetylene & Convolution & {$[51]$} & $1.7 \mathrm{E}-03$ & $1.5 \mathrm{E}-03$ & $2.1 \mathrm{E}-03$ & $1.1 \mathrm{E}-03$ & $1.7 \mathrm{E}-03$ & $7.8 \mathrm{E}-04$ \\
\hline $\mathrm{C}_{4} \mathrm{H}_{5}$ & 53 & 10.6 & 7.95 & Buta-1,3-dien-2-yl & Convolution & $\operatorname{RICS}\left(\mathrm{C}_{4} \mathrm{H}_{6}\right)$ & $2.4 \mathrm{E}-05$ & 7.9E-05 & $2.5 \mathrm{E}-05$ & $6.2 \mathrm{E}-05$ & 3.3E-05 & 3.7E-05 \\
\hline $\mathrm{C}_{4} \mathrm{H}_{6}$ & 54 & 10.6 & 9.1 & 1,3-Butadiene & Convolution & {$[51]$} & $8.5 \mathrm{E}-03$ & $1.0 \mathrm{E}-02$ & $1.0 \mathrm{E}-02$ & $6.3 \mathrm{E}-03$ & $2.2 \mathrm{E}-03$ & $2.7 \mathrm{E}-03$ \\
\hline $\mathrm{C}_{4} \mathrm{H}_{7}$ & 55 & 10.6 & & different, see text & $\operatorname{RICS}\left(1-, 2-, i-\mathrm{C}_{4} \mathrm{H}_{8}\right)$ & {$[50]$} & $6.7 \mathrm{E}-04$ & $1.3 \mathrm{E}-03$ & $8.5 \mathrm{E}-04$ & $7.8 \mathrm{E}-04$ & $1.3 \mathrm{E}-03$ & $2.1 \mathrm{E}-03$ \\
\hline $\mathrm{C}_{3} \mathrm{H}_{6} \mathrm{O}$ & 58 & 10.6 & 10 & Acetone & Direct & {$[50]$} & $5.7 \mathrm{E}-04$ & $1.1 \mathrm{E}-04$ & $2.3 \mathrm{E}-03$ & $2.7 \mathrm{E}-04$ & $2.1 \mathrm{E}-03$ & $3.7 \mathrm{E}-03$ \\
\hline $\mathrm{C}_{5} \mathrm{H}_{6}$ & 66 & 10.6 & 8.6 & 1,3-Cyclopentadiene & $\operatorname{RICS}\left(\mathrm{C}_{5} \mathrm{H}_{8}\right)$ & {$[50]$} & $2.6 \mathrm{E}-04$ & $4.0 \mathrm{E}-06$ & $2.0 \mathrm{E}-04$ & $5.4 \mathrm{E}-06$ & $1.7 \mathrm{E}-04$ & $1.3 \mathrm{E}-05$ \\
\hline $\mathrm{C}_{5} \mathrm{H}_{8}$ & 68 & 10.6 & 9 & Cylopentene & Direct & {$[50]$} & $2.0 \mathrm{E}-04$ & $1.6 \mathrm{E}-03$ & 2.3E-04 & $2.2 \mathrm{E}-03$ & $4.7 \mathrm{E}-04$ & $2.3 \mathrm{E}-03$ \\
\hline $\mathrm{C}_{5} \mathrm{H}_{10}$ & 70 & 10.6 & 9.52 & 3-Methyl-1-butene & $\mathrm{RICS}\left(\mathrm{C}_{5} \mathrm{H}_{8}\right)$ & {$[50]$} & 7.2E-04 & $1.2 \mathrm{E}-03$ & $1.2 \mathrm{E}-03$ & $1.4 \mathrm{E}-03$ & $2.3 \mathrm{E}-03$ & 8.9E-03 \\
\hline $\mathrm{C}_{6} \mathrm{H}_{2}$ & 74 & 10.6 & 9.5 & Triacetylene & Convolution & {$[51]$} & $1.8 \mathrm{E}-04$ & $3.7 \mathrm{E}-05$ & $9.1 \mathrm{E}-05$ & $3.4 \mathrm{E}-05$ & $2.5 \mathrm{E}-04$ & $3.4 \mathrm{E}-05$ \\
\hline $\mathrm{C}_{6} \mathrm{H}_{4}$ & 76 & 10.6 & 9.03 & Benzyne & Convolution & $\operatorname{RICS}\left(\mathrm{C}_{6} \mathrm{H}_{2}\right)$ & $6.0 \mathrm{E}-05$ & 6.6E-06 & 3.9E-05 & 8.3E-06 & $1.2 \mathrm{E}-04$ & $1.3 \mathrm{E}-05$ \\
\hline $\mathrm{C}_{6} \mathrm{H}_{6}$ & 78 & 10.6 & 9.2 & Benzene & Direct & {$[51]$} & $1.6 \mathrm{E}-04$ & 9.2E-05 & $1.2 \mathrm{E}-04$ & $1.2 \mathrm{E}-04$ & $2.7 \mathrm{E}-04$ & $2.8 \mathrm{E}-04$ \\
\hline $\mathrm{C}_{7} \mathrm{H}_{8}$ & 92 & 10.6 & 8.8 & Toluene & Direct & {$[50]$} & $2.1 \mathrm{E}-05$ & 9.4E-06 & $1.7 \mathrm{E}-05$ & $1.2 \mathrm{E}-05$ & 5.4E-05 & 2.7E-05 \\
\hline
\end{tabular}


Table 2. $\mathrm{C}_{3} \mathrm{H}_{4}$ isomers: Allene and propyne peak mole fractions for the three butene flames.

Comparison of experimental (ratio determined with $\mathrm{GC}$ at $3 \mathrm{~mm}$; sum of $\mathrm{C}_{3} \mathrm{H}_{4}$ by MBMS) and numerical maximum mole fractions.

\begin{tabular}{|l|c|c|c|c|c|c|}
\hline & \multicolumn{2}{|c|}{ 1-butene } & \multicolumn{2}{c|}{ 2-butene } & \multicolumn{2}{c|}{ i-butene } \\
\hline & $\mathbf{x}_{\max }$ Exp. & $\mathbf{x}_{\max }$ Model & $\mathbf{x}_{\max }$ Exp. & $\mathbf{x}_{\max }$ Model & $\mathbf{x}_{\max }$ Exp. & $\mathbf{x}_{\max }$ Model \\
\hline Allene & $1.7 \mathrm{E}-03$ & $2.8 \mathrm{E}-03$ & $8.8 \mathrm{E}-04$ & $2.9 \mathrm{E}-03$ & $4.2 \mathrm{E}-03$ & $5.4 \mathrm{E}-03$ \\
\hline Propyne & $2.6 \mathrm{E}-03$ & $4.4 \mathrm{E}-03$ & $2.3 \mathrm{E}-03$ & $5.6 \mathrm{E}-03$ & $8.2 \mathrm{E}-03$ & $1.0 \mathrm{E}-02$ \\
\hline Propyne/allene ratio & 1.50 & 1.57 & 2.64 & 1.98 & 1.93 & 1.90 \\
\hline
\end{tabular}




\section{Figure captions}

Fig. 1. Experimental setup of the MBMS apparatus (top), showing flame chamber, first pumping stage, ionization chamber, and reflectron TOF-MS. Detailed sampling configuration (bottom), including the low-pressure GC sampling interface. Valve positions are indicated: continuous lines: "sampling", broken lines: "measurement".

Fig. 2. Integrated flow analysis of 1 -butene consumption. The thickness of the arrows indicates the contribution of the respective pathway to the total flux of $\mathrm{C}$-atoms (contributions of the consumption of the individual molecule are indicated by percentages next to the arrows).

Fig. 3. Integrated flow analysis of 2-butene consumption. The thickness of the arrows indicates the contribution of the respective pathway to the total flux of $\mathrm{C}$-atoms (contributions of the consumption of the individual molecule are indicated by percentages next to the arrows).

Fig. 4. Integrated flow analysis of $i$-butene consumption. The thickness of the arrows indicates the contribution of the respective pathway to the total flux of $\mathrm{C}$-atoms (contributions of the consumption of the individual molecule are indicated by percentages next to the arrows).

Fig. 5. Main species mole fraction $\left(x_{i}\right)$ and perturbed temperature $(T)$ profiles for the flames of the three butene isomers as a function of height above burner (h). Symbols represent the experimental data, lines represent the modeling results. Equilibrium values are indicated at $32 \mathrm{~mm}$. Perturbed temperature profiles were obtained from the MBMS measurements, with 
NO-LIF calibration at $21.7 \mathrm{~mm}$ indicated in the insert table. T profiles were used as input parameters for the numerical simulation without any changes.

Fig. 6. Selected C3 species profiles. Symbols and thin lines represent the experimental results, numerical results are represented by the corresponding thick lines. Measurements at $\mathrm{h} \leq 1 \mathrm{~mm}$ (open symbols) may be affected by sampling probe effects.

Fig. 7. $\mathrm{C}_{3} \mathrm{H}_{4}$ isomers (allene and propyne). Mole fraction profiles (sum of $\mathrm{C}_{3} \mathrm{H}_{4}$ ) obtained in the MBMS experiment and respective model prediction (upper left panel), and results of the GC analysis for the $\mathrm{m} / \mathrm{z}=40.031$ signal obtained at $\mathrm{h}=3 \mathrm{~mm}$ for the three flames. Note that GC peaks must be corrected by calibration factors (see text) to obtain the quantitative ratios in Table 2.

Fig. 8. $\mathrm{C}_{4} \mathrm{H}_{7}$ and $\mathrm{C}_{4} \mathrm{H}_{6}$ species profiles (sum of isomers). Symbols and thin lines represent the experimental results, numerical results are represented by the corresponding thick lines. Measurements at $\mathrm{h} \leq 1 \mathrm{~mm}$ (open symbols) may be affected by sampling probe effects.

Fig. 9. Species profiles of butadiene destruction products. Symbols and thin lines represent the experimental results, numerical results are represented by the corresponding thick lines. Measurements at $\mathrm{h} \leq 1 \mathrm{~mm}$ (open symbols) may be affected by sampling probe effects.

Fig. 10. Selected $\mathrm{C} 1$ and $\mathrm{C} 2$ species profiles. Symbols and thin lines represent the experimental results, numerical results are represented by the corresponding thick lines. Measurements at $\mathrm{h} \leq 1 \mathrm{~mm}$ (open symbols) may be affected by sampling probe effects.

Fig. 11. Species profiles for sums of $\mathrm{C}_{5} \mathrm{H}_{8}$ as well as $\mathrm{C}_{5} \mathrm{H}_{10}$ isomers. Symbols and thin lines represent the experimental results, numerical results are represented by the corresponding 
thick lines. Measurements at $\mathrm{h} \leq 1 \mathrm{~mm}$ (open symbols) may be affected by sampling probe effects. Note that modeling results are scaled by a factor of 0.25 for both panels.

Fig. 12. Identification of $\mathrm{C}_{5} \mathrm{H}_{8}$ isomers: $\mathrm{GC}$ analysis for $\mathrm{m} / \mathrm{z}=68.063$ at $\mathrm{h}=3 \mathrm{~mm}$ for the three flames, and cold-gas calibration (lower right) for cyclopentene, isoprene, 1,4-pentadiene, and trans-1,3-pentadiene.

Fig. 13. Identification of $\mathrm{C}_{5} \mathrm{H}_{10}$ isomers: $\mathrm{GC}$ analysis for $\mathrm{m} / \mathrm{z}=70.078$ at $\mathrm{h}=3 \mathrm{~mm}$ for the three flames, and cold-gas calibration (lower right) for 3-methyl-1-butene, trans-2-pentene, 2-methyl-1-butene, $n$-pentene, and cis-2-pentene. 

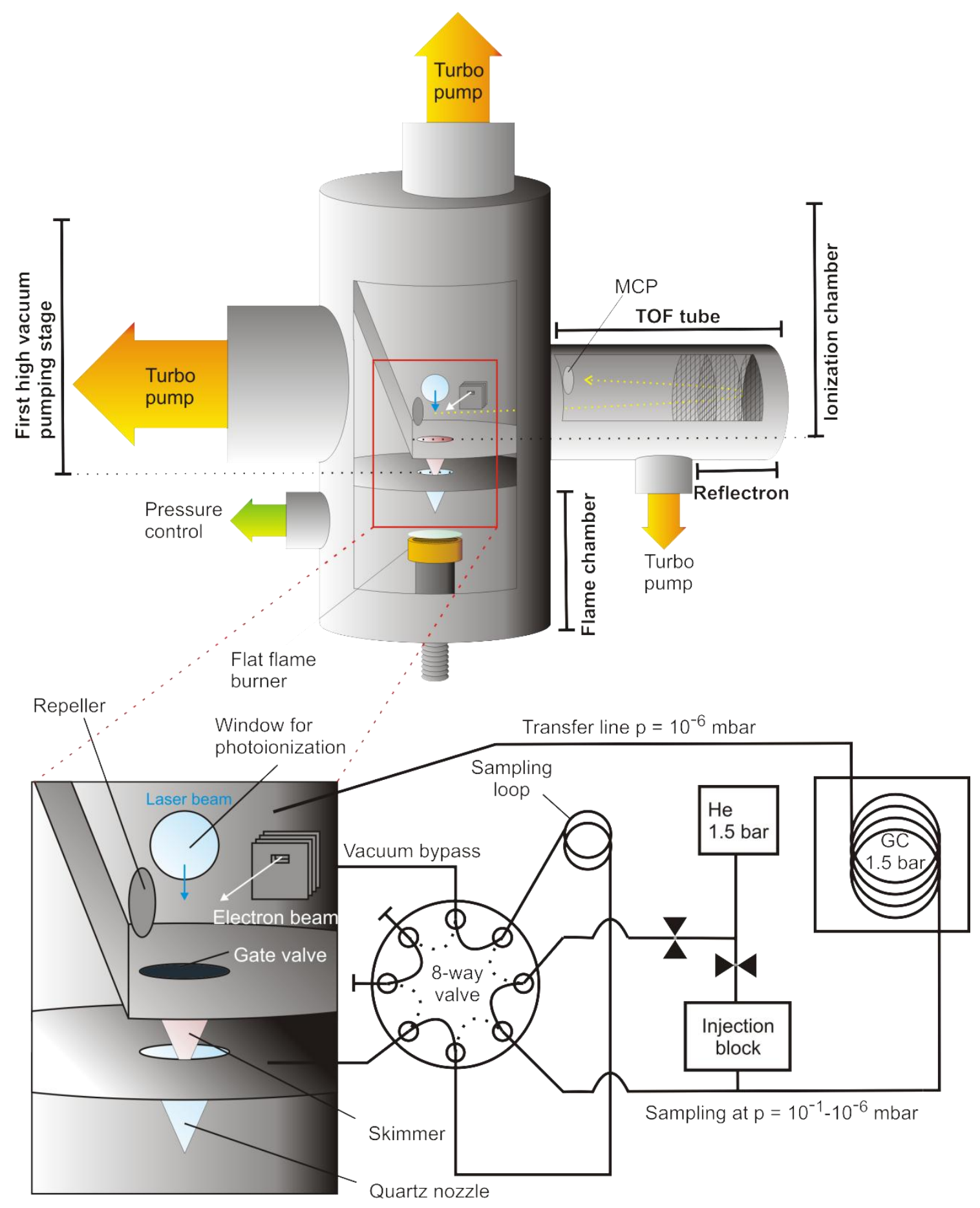

Fig. 1. Experimental setup of the MBMS apparatus (top), showing flame chamber, first pumping stage, ionization chamber, and reflectron TOF-MS. Detailed sampling configuration (bottom), including the low-pressure GC sampling interface. Valve positions are indicated: continuous lines: "sampling", broken lines: "measurement". 


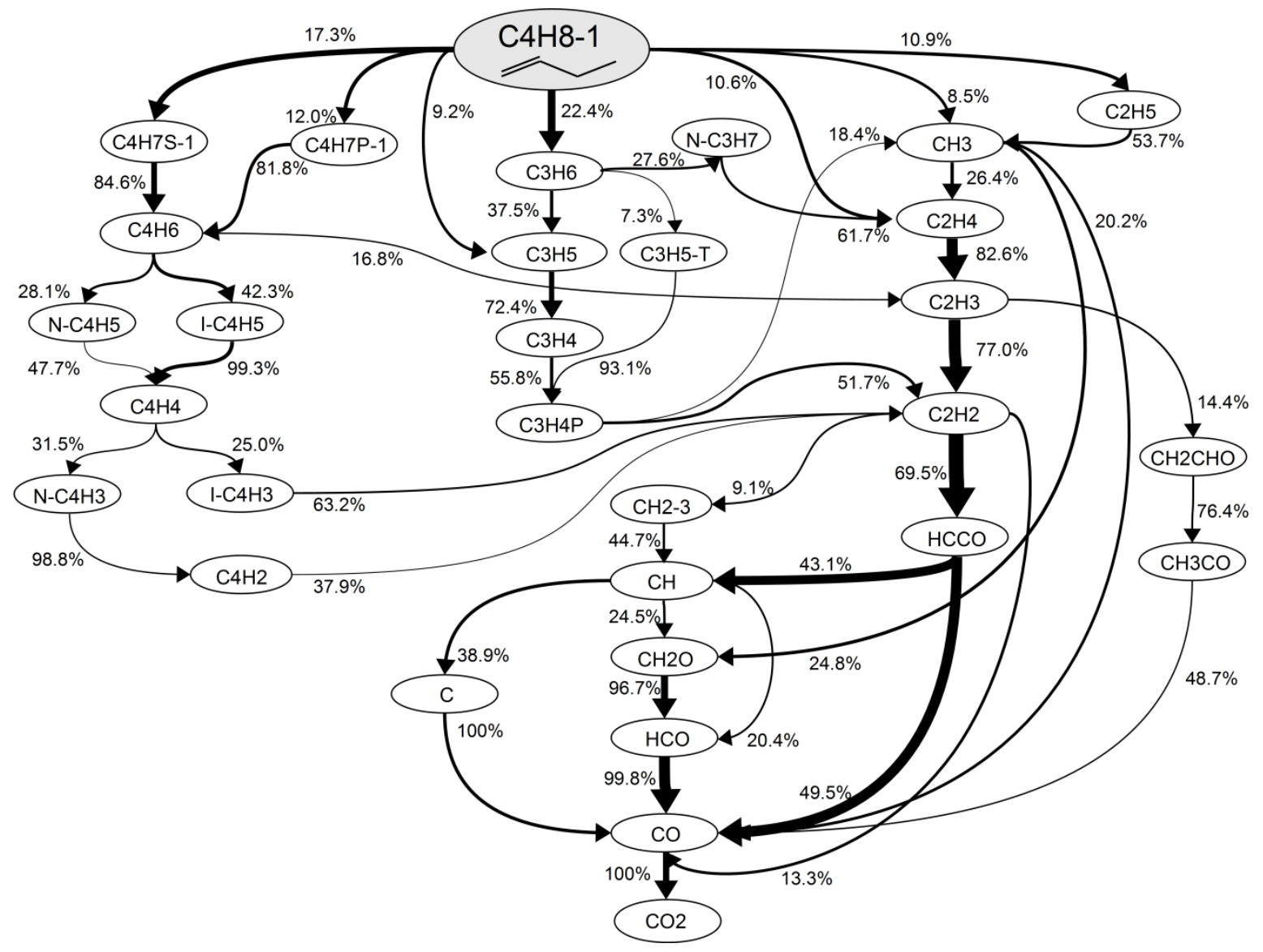

Fig. 2. Integrated flow analysis of 1 -butene consumption. The thickness of the arrows indicates the contribution of the respective pathway to the total flux of $\mathrm{C}$-atoms (contributions of the consumption of the individual molecule are indicated by percentages next to the arrows). 


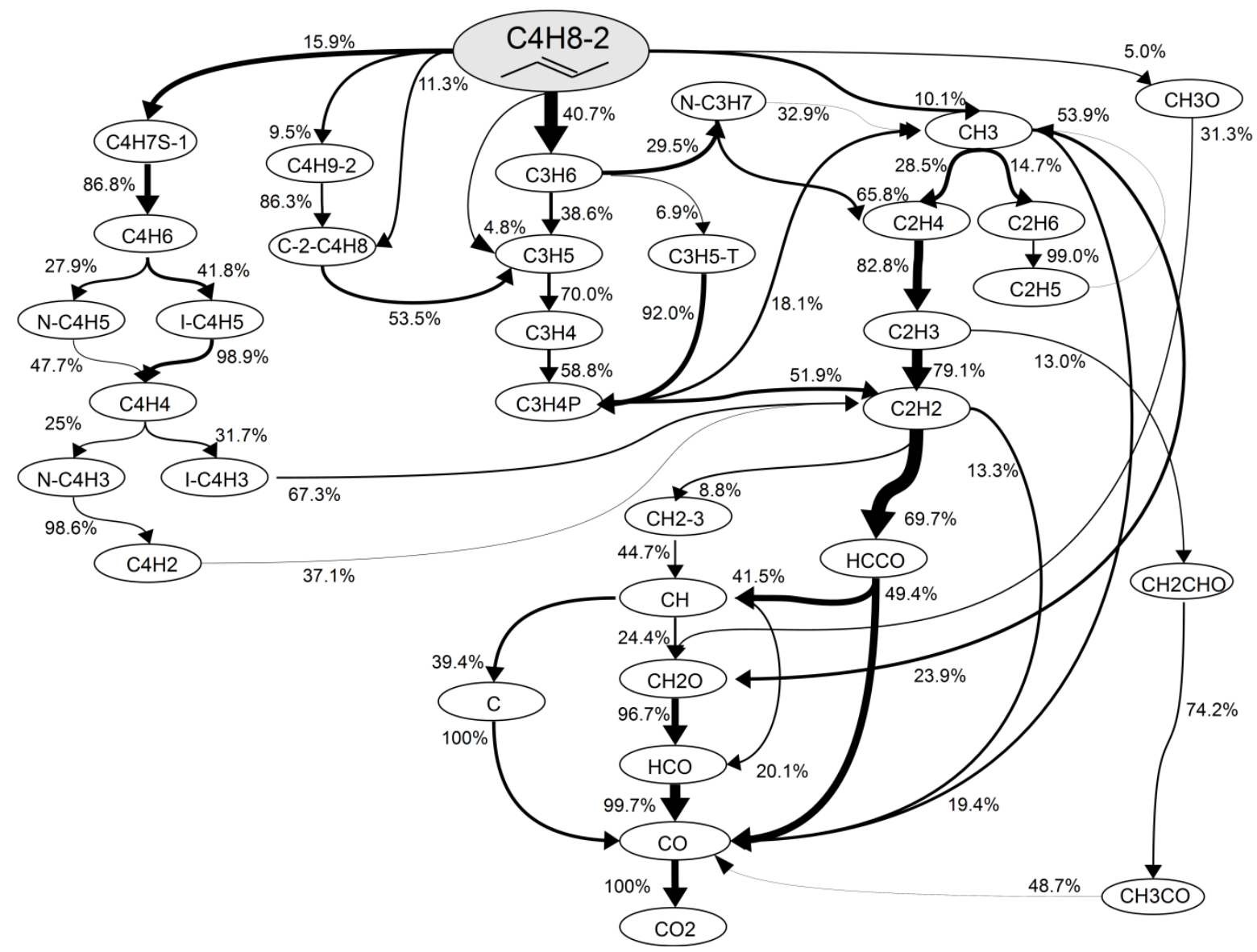

Fig. 3. Integrated flow analysis of 2-butene consumption. The thickness of the arrows indicates the contribution of the respective pathway to the total flux of $\mathrm{C}$-atoms (contributions of the consumption of the individual molecule are indicated by percentages next to the arrows). 


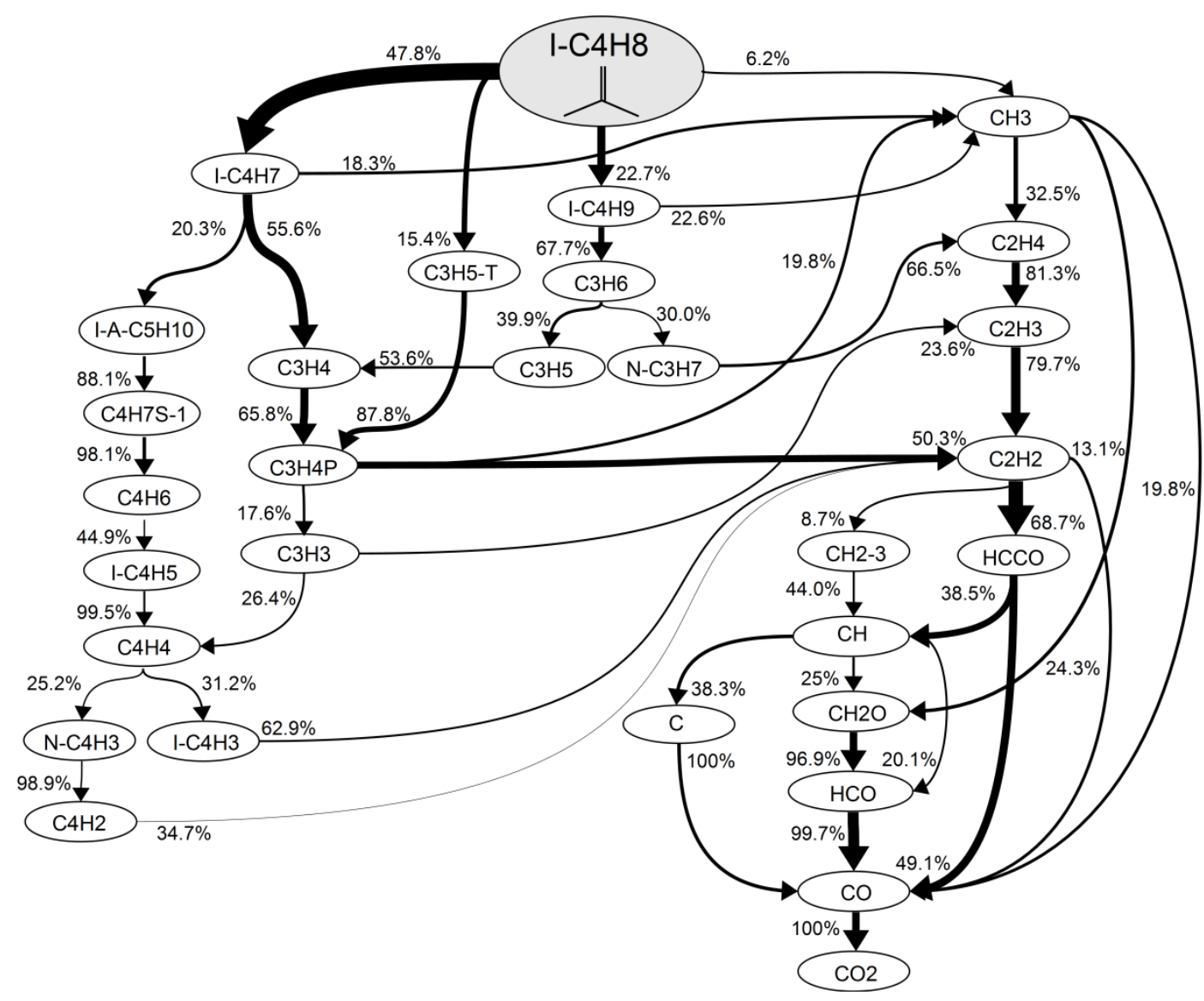

Fig. 4 Integrated flow analysis of $i$-butene consumption. The thickness of the arrows indicates the contribution of the respective pathway to the total flux of C-atoms (contributions of the consumption of the individual molecule are indicated by percentages next to the arrows). 

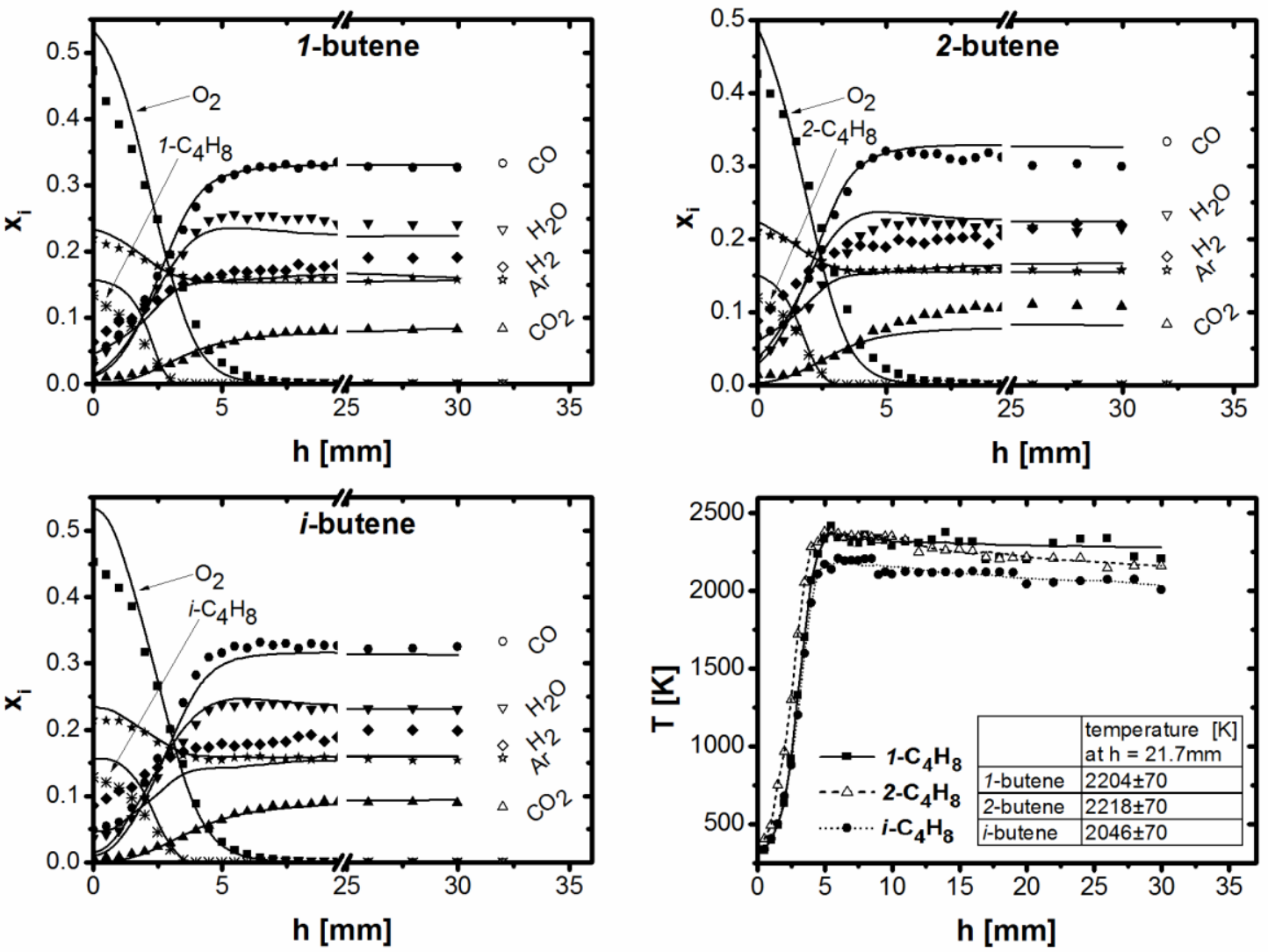

Fig. 5. Main species mole fraction $\left(x_{i}\right)$ and perturbed temperature $(T)$ profiles for the flames of the three butene isomers as a function of height above burner (h). Symbols represent the experimental data, lines represent the modeling results. Equilibrium values are indicated at $32 \mathrm{~mm}$. Perturbed temperature profiles were obtained from the MBMS measurements, with NO-LIF calibration at $21.7 \mathrm{~mm}$ indicated in the insert table. T profiles were used as input parameters for the numerical simulation without any changes. 

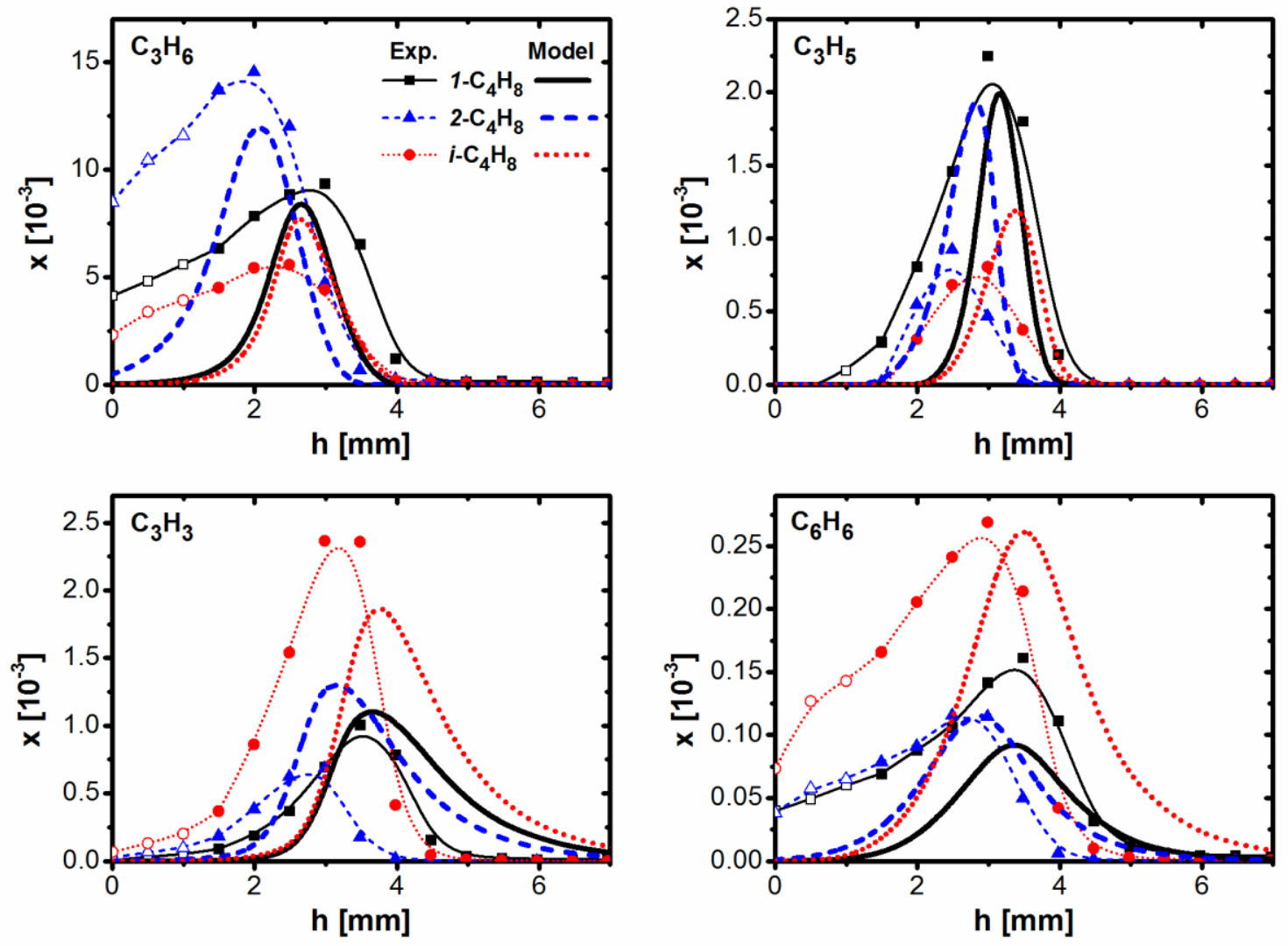

Fig. 6. Selected C3 species profiles. Symbols and thin lines represent the experimental results, numerical results are represented by the corresponding thick lines. Measurements at $\mathrm{h} \leq 1 \mathrm{~mm}$ may be affected by sampling probe effects and are indicated by open symbols. 

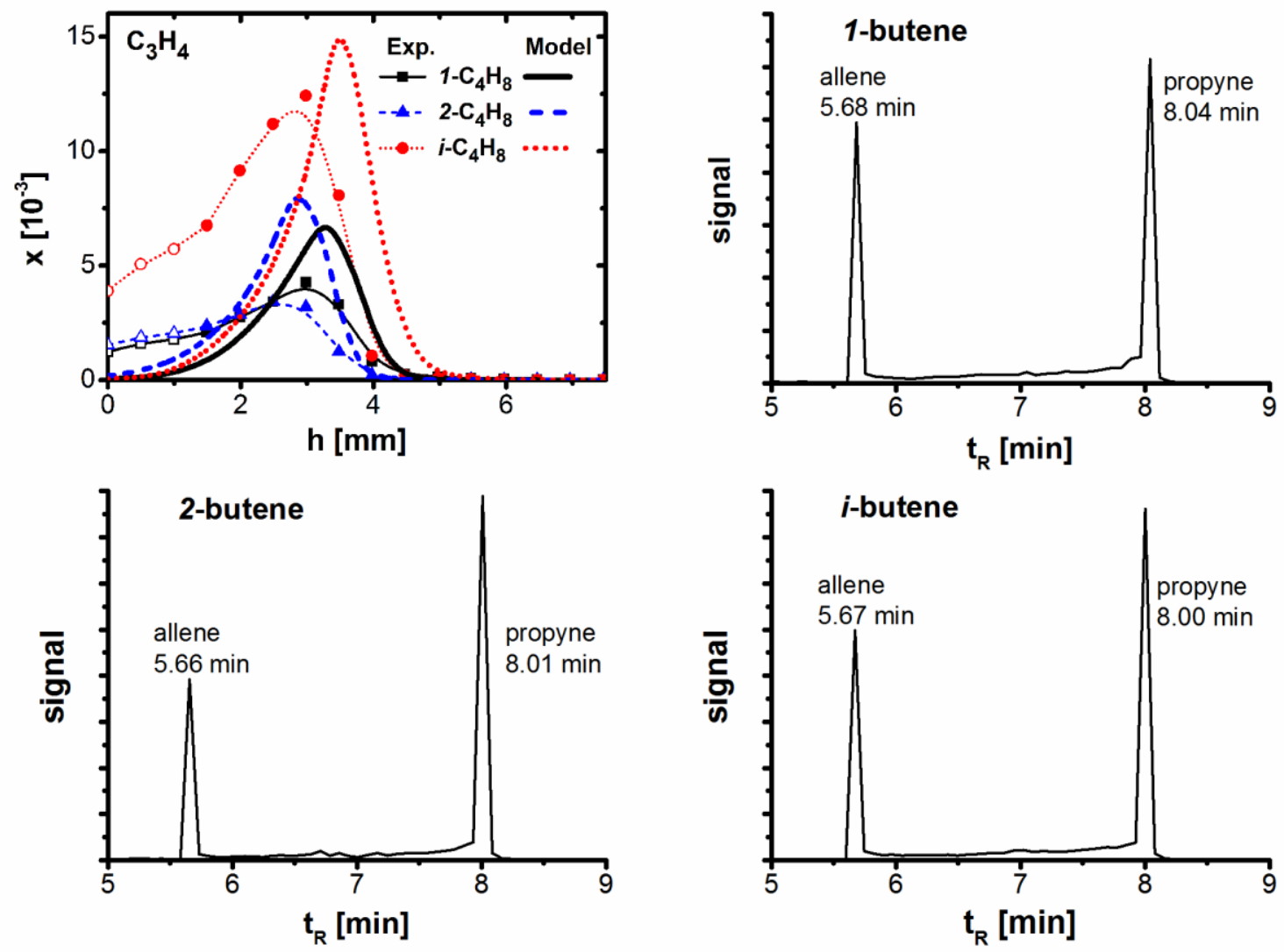

Fig. 7. $\mathrm{C}_{3} \mathrm{H}_{4}$ isomers (allene and propyne). Mole fraction profiles (sum of $\mathrm{C}_{3} \mathrm{H}_{4}$ ) obtained in the MBMS experiment and respective model prediction (upper left panel), and results of the GC analysis for the $\mathrm{m} / \mathrm{z}=40.031$ signal obtained at $\mathrm{h}=3 \mathrm{~mm}$ for the three flames. Note that GC peaks must be corrected by calibration factors (see text) to obtain the quantitative ratios in Table 2. 

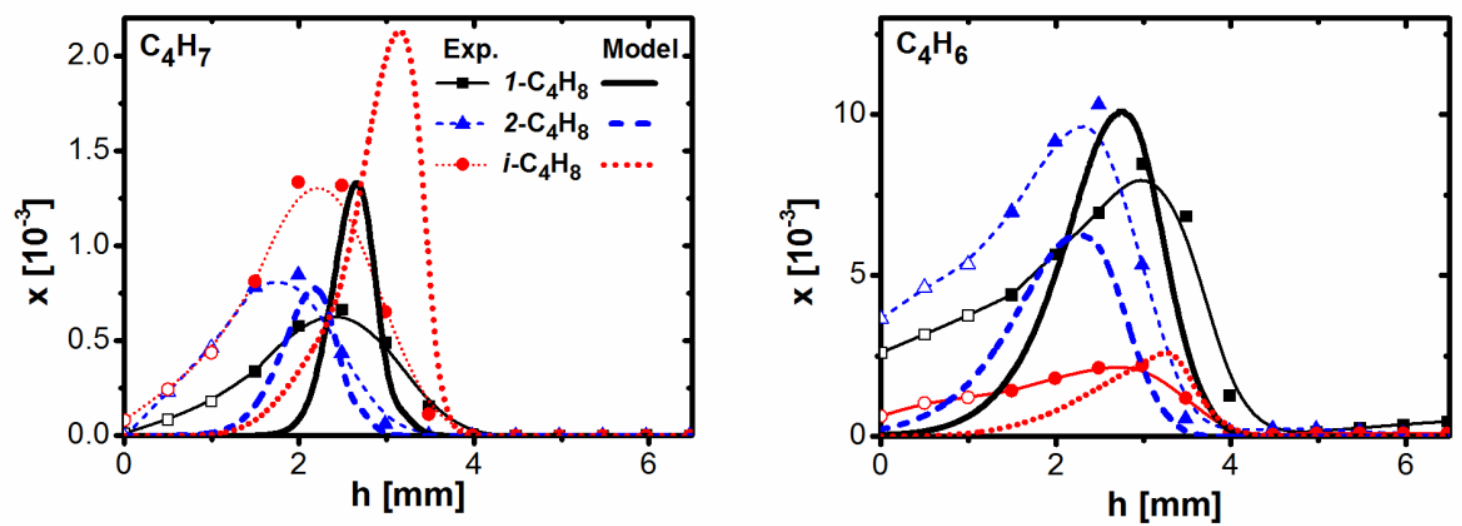

Fig. 8. $\mathrm{C}_{4} \mathrm{H}_{7}$ and $\mathrm{C}_{4} \mathrm{H}_{6}$ species profiles (sum of isomers). Symbols and thin lines represent the experimental results, numerical results are represented by the corresponding thick lines. Measurements at $\mathrm{h} \leq 1 \mathrm{~mm}$ (open symbols) may be affected by sampling probe effects. 

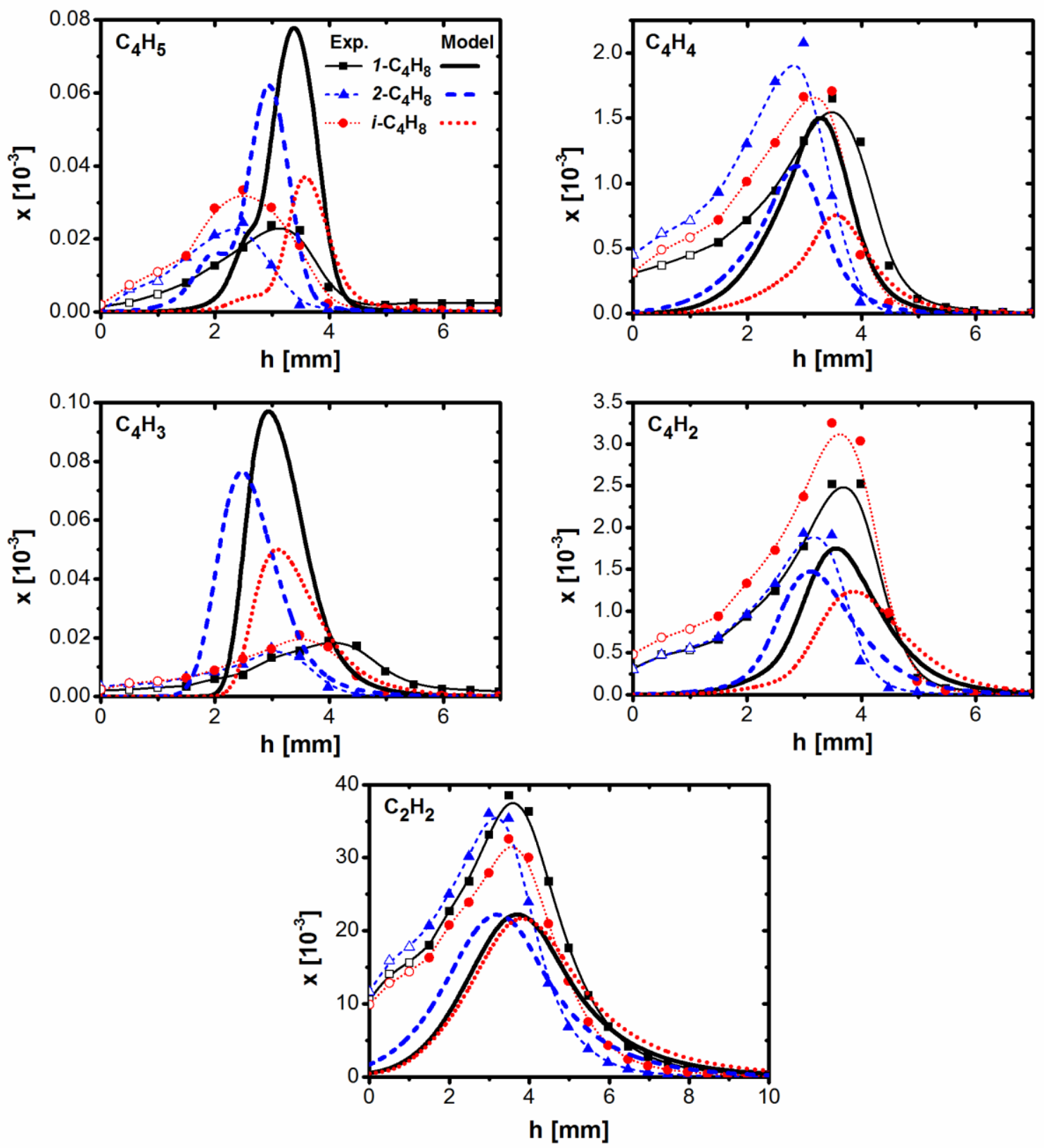

Fig. 9. Species profiles of butadiene destruction products. Symbols and thin lines represent the experimental results, numerical results are represented by the corresponding thick lines. Measurements at $\mathrm{h} \leq 1 \mathrm{~mm}$ (open symbols) may be affected by sampling probe effects. 

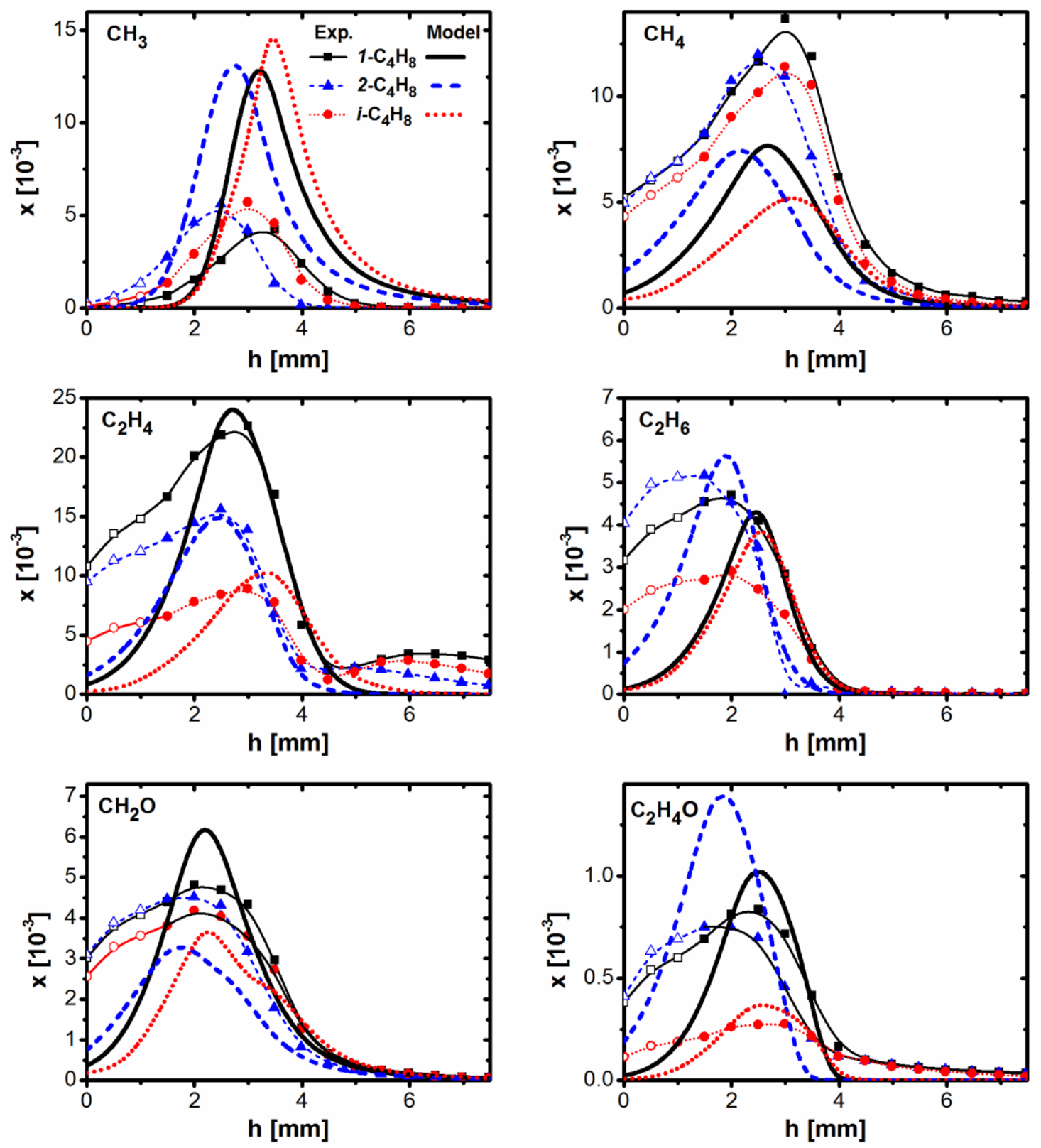

Fig. 10. Selected $C 1$ and $C 2$ species profiles. Symbols and thin lines represent the experimental results, numerical results are represented by the corresponding thick lines. Measurements at $\mathrm{h} \leq 1 \mathrm{~mm}$ (open symbols) may be affected by sampling probe effects. 

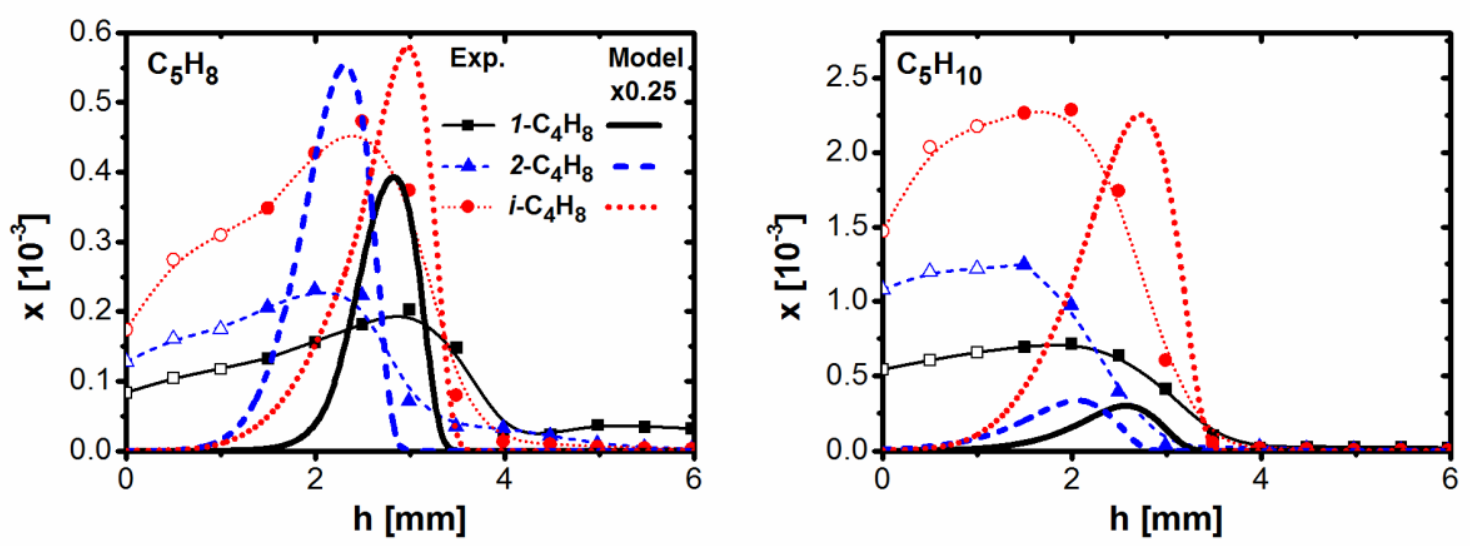

Fig. 11. Species profiles for sums of $\mathrm{C}_{5} \mathrm{H}_{8}$ as well as $\mathrm{C}_{5} \mathrm{H}_{10}$ isomers. Symbols and thin lines represent the experimental results, numerical results are represented by the corresponding thick lines. Measurements at $\mathrm{h} \leq 1 \mathrm{~mm}$ (open symbols) may be affected by sampling probe effects. Note that modeling results are scaled by a factor of 0.25 for both panels. 

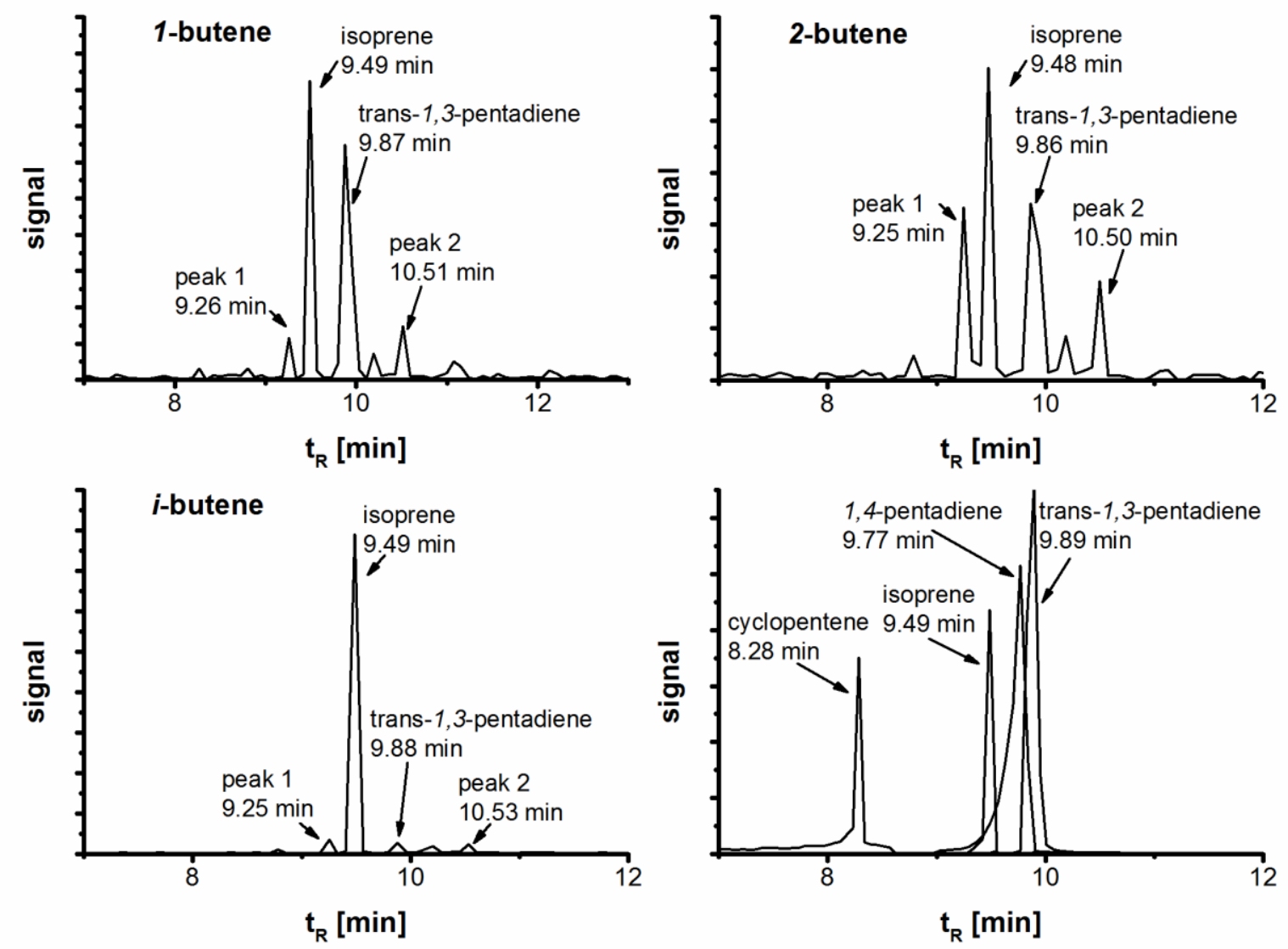

Fig. 12. Identification of $\mathrm{C}_{5} \mathrm{H}_{8}$ isomers: $\mathrm{GC}$ analysis for $\mathrm{m} / \mathrm{z}=68.063$ at $\mathrm{h}=3 \mathrm{~mm}$ for the three flames, and cold-gas calibration (lower right) for cyclopentene, isoprene, 1,4-pentadiene, and trans-1,3-pentadiene. 

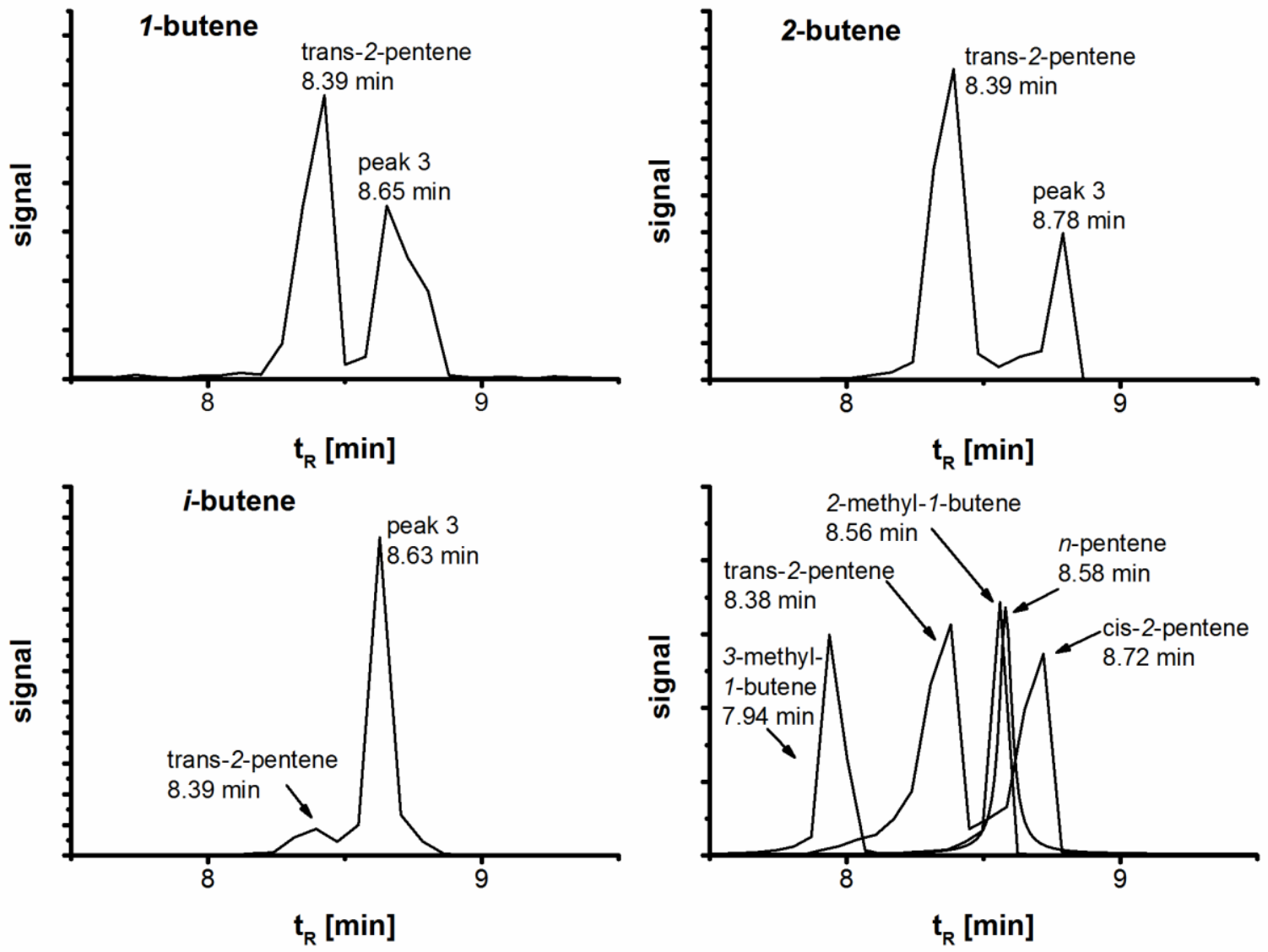

Fig. 13. Identification of $\mathrm{C}_{5} \mathrm{H}_{10}$ isomers: $\mathrm{GC}$ analysis for $\mathrm{m} / \mathrm{z}=70.078$ at $\mathrm{h}=3 \mathrm{~mm}$ for the three flames, and cold-gas calibration (lower right) for 3-methyl-1-butene, trans-2-pentene, 2-methyl-1-butene, $n$-pentene, and cis-2-pentene. 